\title{
Adipocyte nuclei captured from VAT and SAT
}

Suresh Ambati ${ }^{1}$, Ping Yu ${ }^{1}$, Elizabeth C. McKinney ${ }^{1}$, Muthugapatti K. Kandasamy ${ }^{1}$, Diane Hartzell ${ }^{2,3}$, Clifton A. Baile ${ }^{2,3^{\wedge}}$ and Richard B. Meagher ${ }^{1 *}$

\begin{abstract}
Background: Obesity-related comorbidities are thought to result from the reprogramming of the epigenome in numerous tissues and cell types, and in particular, mature adipocytes within visceral and subcutaneous adipose tissue, VAT and SAT. The cell-type specific chromatin remodeling of mature adipocytes within VAT and SAT is poorly understood, in part, because of the difficulties of isolating and manipulating large fragile mature adipocyte cells from adipose tissues.
\end{abstract}

Methods: We constructed MA-INTACT (Mature Adipocyte-Isolation of Nuclei TAgged in specific Cell Types) mice using the adiponectin (ADIPOQ) promoter (ADNp) to tag the surface of mature adipocyte nuclei with a reporter protein. The SUN1 mRFP1Flag reporter is comprised of a fragment of the nuclear transmembrane protein SUN1, the fluorescent protein MRFP1, and three copies of the Flag epitope tag.

Results: Mature adipocyte nuclei were rapidly and efficiently immuno-captured from VAT and SAT (MVA and MSA nuclei, respectively), of MA-INTACT mice. MVA and MSA nuclei contained 1,000 to 10,000-fold higher levels of adipocyte-specific transcripts, ADIPOQ, PPARg2, EDNRB, and LEP, relative to uncaptured nuclei, while the latter expressed higher levels of leukocyte and endothelial cell markers IKZF1, RETN, SERPINF1, SERPINE1, ILF3, and TNFA. MVA and MSA nuclei differentially expressed several factors linked to adipogenesis or obesity-related health risks including CEBPA, KLF2, RETN, SERPINE1, and TNFA. The various nuclear populations dramatically differentially expressed transcripts encoding chromatin remodeler proteins regulating DNA cytosine methylation and hydroxymethylation (TETS, DNMTs, TDG, GADD45s) and nucleosomal histone modification (ARID1A, KAT2B, KDM4A, PRMT1, PRMT5, PAXIP1). Remarkably, MSA and MVA nuclei expressed 200 to 1000-fold higher levels of thermogenic marker transcripts PRDM16 and UCP1.

Conclusions: The MA-INTACT mouse enables a simple way to perform cell-type specific analysis of highly purified mature adipocyte nuclei from VAT and SAT and increases the statistical significance of data collected on adipocytes. Isolated VAT and SAT adipocyte nuclei expressed distinct patterns of transcripts encoding chromatin remodeling factors and proteins relevant to diabetes, cardiovascular disease, and thermogenesis. The MA-INTACT mouse is an useful model to test the impact of caloric intake, dietary nutrients, exercise, and pharmaceuticals on the epigenome-induced health risks of obesity.

Keywords: Epigenetics, INTACT transgenic mouse, Visceral and subcutaneous adipose tissue, Cell-type specific

\footnotetext{
* Correspondence: meagher@uga.edu

'Deceased

${ }^{1}$ Department of Genetics, University of Georgia, Athens, GA, USA

Full list of author information is available at the end of the article
} 


\section{Introduction}

Subcutaneous and visceral adipose tissues, SAT and VAT, become the dominant endocrine organs in obese individuals [1-3]. Increased VAT is linked to insulin resistance, diabetes, hypertension, atherosclerosis, and increased hepatic fat content $[4,5]$. By contrast, obese SAT continues to respond better to insulin and is not as clearly linked to disease. Mature adipocytes (MAs) within SAT and VAT, MSAs and MVAs, respectively, have different developmental histories, distinct programs of gene expression, and dissimilar profiles of endocrine secretion [6-10]. MVAs and MSAs contribute distinctly to increased health risk due to altered metabolic properties and changes in adipokine secretion [11-14]. In general, when compared to tissue form normal weight individuals, obese VAT in particular and to a lesser extent obese SAT secrete harmfully higher levels of angiotensin, TNF $\alpha$, IL1B, SERPINE11 , and LEP as well as lower levels of generally beneficial IL10, ADIPOQ, omentin, APLN, and visfatin [15-19]. Therefore, VAT derived obese MVAs are more pathogenic [4]. Beige adipocytes in SAT, which are metabolically beneficial in normal weight individuals, become much less active with obesity and aging [20-22]. Not only does the number of MAs in VAT and SAT increase with obesity, but the cells themselves become significantly enlarged. Obese MAs promote inflammation, recruit macrophages, and predispose obese individuals to health risks, including the increased occurrence of cardiovascular disease, cancer, and diabetes [4, 23-25]. Hence, there has been intense interest in recent years in understanding the role of MAs in obesity-related comorbidities.

Epigenetics is by its origin the study of cell-type specific differences [26-31]. While cell type specificity may be the mantra of epigenetic analyses, few studies are performed at the cell-type specific level despite data showing the statistical significance of working at this level. As an example of the importance of performing cell-type specific analyses, among the seven major classes of peripheral blood leukocyte types in healthy human subjects, the two most similar (CD4 and CD8 T cells) and the two most dissimilar (CD8 and eosinophils) white blood cell types differ at 45,000 (9\%) and 190,000 (40\%), respectively, of 475,000 DNA 5 '-methylcytosine $(5 \mathrm{mC})$ residues at informative CG dinucleotide sites [32]. Hence "whole blood methylation results might be unintelligible" because the data represent the weighted average of cell type differences. In addition, disease-related stress may cause the reprogramming of hundreds of $5 \mathrm{mC}$ sites within a single cell type [33, 34]. Studies of systemic lupus erythematosus (SLE) identified hundreds of $5 \mathrm{mC}$ sites in CD4+ T cells associated with the disease phenotype with median $\mathrm{p}$ values of $\sim 10^{-7}$, while median $p$ values of $\sim 10^{-3}$ were found associated with SLE when DNA from the whole blood leukocyte fraction was examined [33, 35].
In short, the extra effort involved in examining enriched cell-type specific populations from a tissue may be expected to produce dramatically more meaningful epigenetic data [32].

While there is little reason to doubt that epigenetic reprogramming of obese adipocytes within their tissue context is an important component of disease risk [36-43], there are considerable challenges to performing cell-type specific epigenetic analysis of tissuederived MAs. Adipose tissues comprise a complex mixture of cells including adipocytes, diverse endothelial cells and leukocytes, and various multipotent progenitor cell types. Obese SAT and VAT may have an additional bias in the weighted average of cell types, because the number of inflammatory leukocyte cell types may increase several-fold over that found in the tissue of normal weight individuals [44-46]. Another bias may be introduced during cell isolations. MAs are extremely large often ranging from 50 to 120 microns in diameter, generally having a single lipid droplet. They may be enzymatically dissociated and enriched by floatation away from other cell types [47], but they are still difficult to isolate and manipulate efficiently due to their fragile structures and tendency to lyse rapidly with handling or while sitting on ice. Even larger MA cell sizes are observed in obese VAT and SAT, which inherently exacerbates problems of cell manipulation. By contrast, various classes of multipotent and progenitor adipose tissue derived stem cells (ADSCs) and dedifferentiated adipocyte-derived progeny cells (DFAT cells) may be isolated intact and viable from SAT and VAT, in part, because they are small (15 to 25 microns) and relatively stable cells [48-51]. In short the physiology of adipocytes does not favor their isolation relative to other cells in VAT and SAT.

Herein, addresses the problem of cell-type specific analysis of chromatin structure in MAs by applying INTACT technology (isolation of nuclei tagged in specific cell types) to MAs in a transgenic mouse model. INTACT has been used to isolate nuclei from specific cell types tagged in transgenic Arabidopsis thaliana, Caenorhabditis elegans, and Drosophila melanogaster [28, 52-54]. We developed a protocol that simplifies the isolation of cellular nuclei from VAT, SAT, and BAT. We screened for Nuclear membrane Targeted Fusion proteins (NTFs), which when expressed from an adiponectin derived promoter (ADNp), delivered both a fluorescent reporter and epitope tags to the exterior surface of MA nuclei. Our strategy for constructing a MA-INTACT mouse is outlined in Fig. 1. MA nuclei from transgenic mice expressing ADNp::SUN1mRFP1Flag are highly enriched after capture on immuno-paramagnetic beads. Captured and uncaptured classes of SAT and VAT nuclei differentially expressed many of the 


\section{a ADNp::SUN1mRFP1Flag}
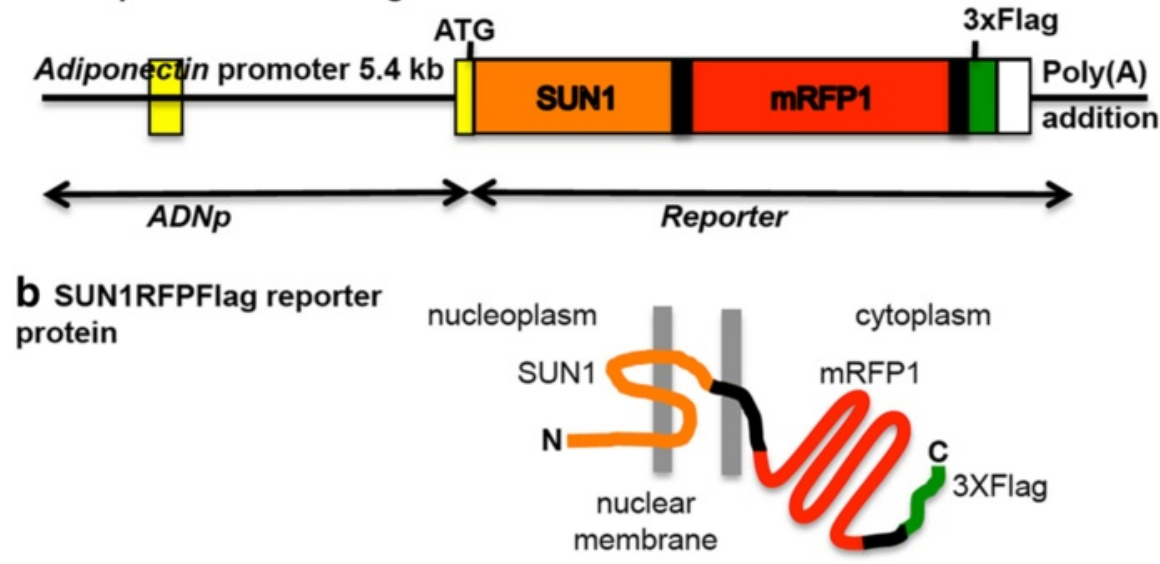

C SUN1RFPFI reporter expressed in nuclei of mature adipocytes in tissue

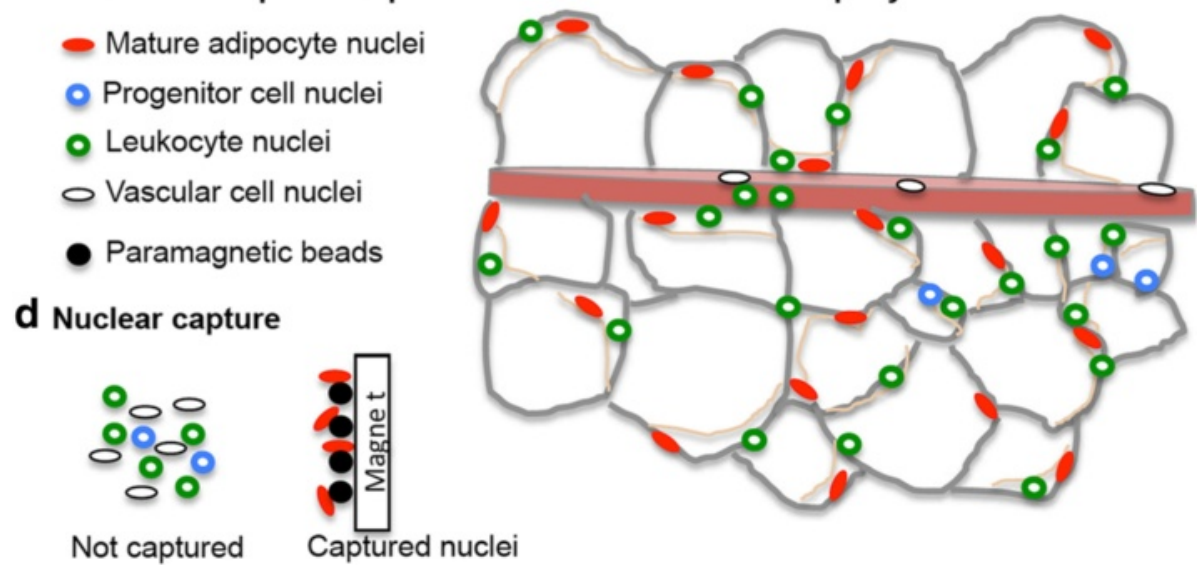

Fig. 1 Strategy for implementing INTACT to capture adipocyte nuclei. a The ADNp::SUN1mRFP1Flag gene construct. This promoter is a truncated $5.4 \mathrm{~kb}$ version of the mouse adiponectin promoter ( $A D N p)$ modified slightly from one described previously [63]. This promoter was fused first to the N-terminal portion of mouse SUN1, then via a flexible linker peptide to the enhanced red fluorescent protein mRFP1, which was fused in frame through a linker peptide to a epitope Flag tag containing three distinct Flag sequences (3xFlag). The ADIPOQ promoter region contains a 5' upsteam exon (yellow) and intron, a 5' mRNA UTR, and the ATG start codon. The 3' UTR and poly(A) addition site are from SV40 in the pcDNA3.1 vector. More detailed maps are shown in Additional file 1: Figure S1 and Additional file 3: Figure S3. b Proposed deposition of the SUN1mRFP1Flag protein tethered to the inner nuclear membrane and tagging the exterior of the nucleus. c Diagram of adipose tissue comprised of MAs expressing the SUN1mRFP1Flag tag and many non-target cell types (progenitor cells, leukocytes, endothelial cells). $\mathbf{d}$ Capture and enrichment of MA nuclei away from other cellular nuclei on paramagnetic beads labeled with anti-mRFP1, anti-GFP or anti-Flag. A total of four constructs designed from 3 nuclear transmembrane proteins were examined (Table 1)

expected cell type markers, but expressed distinctly different chromatin remodeling factors and markers of thermogenesis.

\section{Materials and methods \\ Reagents}

Anti-RFP (ab34771), Anti-Flag (ab106259), anti-CD4 (ab846) antibodies were obtained from Abcam. AntimRFP1 rabbit polyclonal antibody ( $\mathrm{rab} \mathrm{pAb}$ ) was prepared by Thermo Scientific Pierce Antibodies using their 2 Rabbit, 90 Day Protocol. We expressed the 672 bp mRFP1 CDS with a C-Terminal 6xhis tag in E. coli from the PET15b vector. After IPTG induction the protein levels were very high and the cells turned red. The red protein was highly enriched on a column with nickel charged resin, Ni-NTA Superflow (Qiagen 30410). The $\operatorname{IgG}$ fraction of anti-mRFP1 antibody was enriched by ammonium sulfate fractionation [55] and dialyzed in phosphate buffered saline $\left(10 \mathrm{mM} \mathrm{H} \mathrm{H}_{2} \mathrm{NaPO}_{4} / \mathrm{HNa}_{2} \mathrm{PO} 4\right.$ $\mathrm{pH}=7.4,150 \mathrm{mM} \mathrm{NaCl}, 0.1 \%$ sodium azide) for storage at $4{ }^{\circ} \mathrm{C}$.

\section{NTF fusion proteins to tag adipocyte nuclei}

An adiponectin promoted vector plasmid pADNpcDNA3.1 KanR was constructed to drive NTF expression in MAs (Additional file 1: Figures S1, Additional file 2: Figure S2). Four constructs were made from three NTFs with the potential to tag the surface of adipocyte nuclei with an 
epitope(s) to be used in immuno-capture experiments (Additional file 3: Figure S3, Additional file 4: Figure S4, Additional file 5: Figure S5, Additional file 6: Figure S6). All three proteins are anchored via $\mathrm{N}$-terminal domains facing into the nucleoplasm and C-terminal domains facing outward toward the cytoplasm. Mouse SUN1 makes three passes through the inner nuclear membrane. One construct, SUN1mRFP1Flag, was made by fusing the Nterminus of mRFP1 and a triple Flag tag to the C-terminal end of a SUN1 N-terminal fragment (i.e., lacking the normal SUN1 C-terminus). Mouse Nesprin-3 (Nesp3) makes one pass through the outer nuclear membrane. Two constructs were made based on Nesp3. The first, Nesp3mRFP1Flag, is a simple fusion of mRFP1 and 3XFlag domain from SUN1mRFP1Flag to the C-terminus of an NTerminal Nesp3 fragment (i.e., lacking the normal Cterminus of Nesp3). Because the C-terminus of Nesp3 has been implicated in its localization we made a second construct. In Nesp3mRFP1Nesp, we added the C-terminal domain of Nesp3 to the end of mRFP1, replacing the 3XFlag sequence in Nesp3mRFP1Flag. In each of the three above constructs, (GlySer) ${ }_{4-5}$ Gly linkers separate the different domains. Arabidopsis RANGAP1 associates with the cytoplasmic side of the nuclear pore complex. We used the same RANGAP1GFP reporter sequence that was used in the first successful report of INTACT technology in Arabidopsis [28]. All four constructs were inserted into the adiponectin expression vector. Construct sequences will be available at NCBI's sequence repository (DDBJ/EMBL/ Genbank - INSDC) once this manuscript is accepted for publication.

\section{Cell culture}

Mouse embryo fibroblast cell line (3T3-L1, ATCC \#CL-173) was purchased from American Type Culture Collection (Manassas, VA). Cells were cultured in DMEM (Invitrogen \#12800017) containing $10 \%$ bovine calf serum (Life Technologies, \#16170078), $1 \%$ penicillin-streptomycin-glutamine (Life Technologies, \#10378016) and $1 \%(\mathrm{v} / \mathrm{v}) 100 \mathrm{mM}$ sodium pyruvate (Life Technologies, \#11360070) at $37{ }^{\circ} \mathrm{C}$ in $95 \%$ air-5\% $\mathrm{CO}_{2}$.

\section{Nucleofection}

3T3-L1 preadipocytes $\left(2 \times 10^{6}\right.$ cells $)$ were nucleofected with each construct $(0.1,0.5,1$, and 2 ug DNA) using the Amaxa Cell Line Nucleofector Kit V (Lonza \#VCA1003). Each nucleofection was seeded into a 6 well microtiter plate in calf serum medium and expanded for 6 days with700 ug of neomycin G418 (Invitrogen \#10131035). Cells were transferred to $50 \mathrm{~mm}$ petri plates and grown. Two days after reaching confluence, cells were induced to differentiate for two days with DMEM media containing $10 \%$ fetal bovine serum (FBS) (Life
Technologies, \#10437028), $0.5 \mu \mathrm{M}$ 3-isobutyl-1-methylxanthine (IBMX, Sigma \#I5879), $1 \mu \mathrm{M}$ dexamethasone (Sigma \#D4902) and $167 \mathrm{nM}$ insulin (Sigma \#I-6634). Cells were maintained for the next two days in DMEM medium containing $10 \%$ FBS and 167 nM insulin. Cells were cultured for an additional 4 days in $10 \% \mathrm{FBS} /$ DMEM medium, during which time they differentiated into MAs filled with lipid-droplets. MAs were maintained in $10 \%$ FBS/DMEM medium and analyzed daily for green or red fluorescent protein expression by fluorescence microscopy (FM) on Nikon (Eclipse TE2000-S) inverted microscope.

\section{Transgenic MA-INTACT mice expressing SUN1mRFP1Flag nuclear tag in MAs}

A $12.4 \mathrm{~kb}$ NotI fragment from our plasmid vector containing ADNp::SUN1mRFP1Flag reporter sequence (Additional file 1: Figure S1 \& Additional file 3: Figure S3) was used to construct transgenic (Tg) mice in the C57 Black 6 (C57BL/ $6 \mathrm{~N})$ background. Among the mice identified with the randomly integrated transgene, four mice expressed SUN1mRFP1Flag mRNA in tail snip mRNA preparations (Additional file 7: Figure S8). We identified two founding mice, C023 and D025 (C and D lines), whose offspring expressed significant amounts of the SUN1mRFP1Flag mRNA in BAT, VAT, and SAT. We generated two inbred mouse colonies, C023 and D025, homozygous for the transgene. Both appear healthy and long-lived. The studies reported herein represent data from hemizygous F2 and F3 generation animals used in breeding.

\section{Enrichment of nuclei}

The following rapid protocol for isolating adipose tissue cellular nuclei or nuclei from transfected 3T3-L1 cells follows closely to that which we published recently for brain cell nuclei [30] (Additional file 8: Figure S7). Freshly dissected and minced mouse tissue or 3T3-L1 adipocytes were treated for $15 \mathrm{~min}$ to $1 \mathrm{hr}$ in four volumes $(\mathrm{w} / \mathrm{v})$ of 0.3SPBSTA $(0.3 \mathrm{M}$ Sucrose, $20 \mathrm{mM}$ KH2PO4, $20 \mathrm{mM} \mathrm{Na} \mathrm{HPO}_{4}, \mathrm{pH}=7.2,137 \mathrm{mM} \mathrm{NaCl}$, $3.0 \mathrm{mM} \mathrm{KCl}, 0.1 \%$ Triton X 100, $0.1 \%$ sodium azide), plus $3.7 \%$ freshly added formalin. Tissue was washed twice with phosphate buffered saline. Tissue samples (100 to $200 \mathrm{mg}$ ) were homogenized by hand in a $1.5 \mathrm{ml}$ microfuge tube with a plastic pestle for $1 \mathrm{~min}$ in 6 volumes of $0.3 \mathrm{SPBSTA}$. The homogenate was filtered through small pieces $(5 \times 5 \mathrm{~cm} \mathrm{sq})$ of Miracloth (Calbiochem, \#475855) suspended loosely over a small funnel. This prevented nuclei from being trapped with large pieces of cytoplasm during the subsequent centrifugation and increased the yield of nuclei several fold. Nuclei were centrifuged through a sucrose cushion (1.4 M sucrose, in 1.4SPBSTA) in a swinging bucket rotor in a refrigerated centrifuge $\left(4{ }^{\circ} \mathrm{C}\right)$ at $3,000 \mathrm{xg}$ for $15 \mathrm{~min}$. The 
nuclear pellet was gently re-suspended in 10 volumes of 0.3 M SPBSTA Microscopic assays using differential interference phase microscopy (DIC) combined with DAPI staining for DNA suggested that the nuclei were approximately $80 \%$ pure, relative to visible debris that did not stain with DAPI (Additional file 8: Figure S7). All reagents were purchased from Thermo Fisher (Waltham, MA), unless stated otherwise.

\section{Immuno-capture of nuclei}

Anti-RFP, anti-FLAG, anti-CD4, anti-CD8, anti-mRFP1 antibodies were coupled to 2.8 micron diameter protein G supraparamagnetic Dynabeads (ThermoFischer Scientific, \#10004D). Bead protocols including the coupling were handled as per the manufacturer's instructions. Briefly, antibody coupled beads were incubated with nuclei prepared from SUN1mRFP1Flag nucleofected mice and differentiated 3T3-L1 adipocytes and washed extensively to remove uncaptured nuclei. The first uncaptured fraction was assayed in parallel. During the wash steps the bead-bound nuclei were repeatedly pulled to the side of $1.5 \mathrm{ml}$ microcentrifuge tubes for $1 \mathrm{~min}$ using neodymium magnets (DynaMag ${ }^{\text {Tw }}-2$ Magnet rack, \#12321D, ThermoFischer Scientific).

\section{Assays of nuclear transcript levels}

Relative quantities (RQ) of nuclear RNA levels from whole VAT, SAT, and BAT tissue, total isolated nuclei, captured and uncaptured nuclei were quantified with qRT-PCR assays. The RQ of transcripts were calculated based on the $\mathrm{dCT}$ method including the standard deviation from the mean (Livak and Schmittgen, 2001). Primers are listed in Additional file 9: Table S1. SDHA mRNA was used as the endogenous control to calculate $R Q$, because in repeated assays its levels, based on cycle threshold values (CTs), varied less than 1 - to 1.8 -fold relative to input cDNA among various samples of captured and uncaptured nuclear cDNA preparations, similar to what we described for fractionated brain cellular nuclei [56]. Based on CT values, $18 S$ rRNA and betaactin [57] were also reasonably equivalently expressed among cDNA samples and would have been reasonable endogenous controls, but their CT values varied slightly more than SDHA among nuclear RNA samples.

RNA from fresh or formalin fixed nuclei was prepared using an RNeasy FFPE kit (Qiagen \#73504). If formalin treated nuclei were used, a heat treatment of $90{ }^{\circ} \mathrm{C}$ for $1 \mathrm{~h}$ was included, after the proteinase $\mathrm{K}$ digestion in PKD buffer to hydrolyze off the formalin [56]. The heataccelerated hydrolysis of formalin crosslinks is well established (Fraenkel-Conrat and Olcott, 1948). RNA was quantified using a Qubit RNA Assay Kit (Life Technologies, \#Q32855). The yield of RNA from 100,000 fixed sorted nuclei varied from 0.5 to $1 \mu$ g. $500 \mathrm{ng}$ samples of RNA were reverse transcribed (RT) into cDNA using qScript cDNA SuperMix (Quanta BioSciences, \#95048). After RT,0.5 $\mu$ l of RNase H at 5 units/ $\mu$ l (New England Biolabs, \#M0297S) was added to the $20 \mu \mathrm{l}$ reaction and incubated at $37{ }^{\circ} \mathrm{C}$ for 20 min. cDNA yield was quantified using the Qubit ssDNA (single strand DNA Assay Kit \#Q10212). 5 ng of cDNA was used per reaction in qRT-PCR assays. Primers are described in Additional file 9: Table S1. Each assay was run in triplicate and the standard error calculated to give the error bars shown. Three biological replicates gave similar results.

\section{Statistical analysis}

The mean \pm standard error of the mean (SEM) is presented for various bar graph data. The qRT-PCR data were further analyzed by one-way ANOVA with post hoc Tukey's HSD test using Statistica software 6.1 (StatSoft; Tulsa, OK, USA). Noteworthy statistical comparisons are indicted in the figures with * for $p<0.05$, * for $p<0.01$, and ${ }^{* * * *}$ for $p<0.001$ and some $\mathrm{p}$ values are also stated in the text.

\section{Results}

\section{A mature-adipocyte-specific expression vector}

Adiponectin (ADIPOQ) is one of the most abundant adipose-tissue derived hormones and has multiple antimetabolic and anti-inflammatory properties [58]. ADIPOQ is expressed in MAs from SAT and VAT and a subset of non-thermogenic adipocytes from BAT, but is not significantly expressed in other adipose tissuederived cell types including endothelial cells, leukocytes, and preadipocytes [59-61]. ADIPOQ is expressed in a few other cell types in the brain [62] that will not affect our targeting of MAs for capture from adipose tissue. $A D I P O Q$ promoter driven transcript expression is more specific for MAs than is expression from the promoters of two other commonly used marker genes expressed in adipocytes PPARg and FABP4 [63]. Therefore, we used an $A D I P O Q$ promoter to express INTACT constructs that might tag MAs.

We engineered an mouse adiponectin promoter (ADNp) expression vector (ADNppcDNA3.1) based on a truncated $5.4 \mathrm{~kb}$ version of the full length promoter reported previously to retain its adipocyte cell-type specificity [63]. ADNp was incorporated into the backbone of the commonly used expression vector pcDNA3.1 (NeoR) (Materials and Methods, Additional file 1: Figure S1). To test the specificity and transcriptional activity of this vector, we inserted the coding sequence (CDS) of a red fluorescent protein, mRFP1, to make a $A D N p:: m R F P 1$ reporter (Additional file 2: Figure S2) [64]. Assaying red fluorescent protein (RFP) avoids the low level of endogenous green fluorescence observed in some adipose tissues. Relative to other 
RFPs, mRFP1 has the advantages of a modestly high fluorescence extinction coefficient and a rapid protein maturation rate. Furthermore, mRFP1 does not form a multimeric cytoplasmic aggregate as do many other fluorescent proteins, which might interfere with its efficient localization to the nuclear membrane.

$A D N p:: m R F P 1$ was nucleofected into 3T3-L1 preadipocytes. After 6 days of G418 selection for the linked neomycin resistance marker NeoR, cells were transferred to adipocyte differentiation medium. No red fluorescence was observed in nucleofected preadipocytes during cellular expansion prior to differentiation. mRFP1 fluorescence was detected in some cells 3 or 4 days after initiating differentiation and red fluorescence was very strong in many clusters of cells by 5 to 7 days (Table 1 ). We did not observe an obvious change in overall fluorescence intensity even after 14 days, except that cells filled with oil bodies showed little fluorescence. As shown in Fig. 2a, mRFP1 fluorescence was observed surrounding newly formed oil bodies within MAs. Hence, the ADNp promoter in ADNppcDNA3.1 exhibited sufficient specificity and strength to warrant its use in tagging MA nuclei.

\section{Screening nuclear targeted fusion proteins for an effective INTACT construct}

Little is known about the expression and molecular conformation of nuclear transmembrane proteins specific for MAs. Therefore, we tested the ability of portions of three nuclear transmembrane proteins that have been characterized in other cell types and organisms, SUN1, Nesprin 3, and RANGAP1, to target fluorescent reporters to the surface of adipocytes. Four distinct constructs based on these three genes were cloned into the multi-linker in ADNppcDNA3.1, replacing the mRFP1 gene in ADNp::mRFP1 (Table 1, Additional file 3: Figure S3, Additional file 4: Figure S4, Additional file 5: Figure S5, Additional file 6: Figure S6).

3T3-L1 preadipocyte cultures were nucleofected with each construct, subjected to neomycyin G418 selection and expansion for 6 days, and then differentiated into
MAs. Live cells in culture dishes were screened by fluorescence microscopy for mRFP1 red or GFP green fluorescence associated with each construct. No fluorescence was detected prior to differentiation for any of the constructs, confirming again that the $5.4 \mathrm{~kb}$ ADNp promoter utilized was not leaky in preadipocytes. While all reporters fluorescently tagged MA nuclei, they varied widely in both the timing of first detection and the strength of nuclear fluorescence (Table 1). SUN1mRFP1Flag and Nesp3mRFP1Nesp proteins were both detected by day 7 , after initiating differentiation, but the red fluorescence from the SUN1 based construct was considerably stronger than for the Nesprin 3 based construct. It took a few more days before we first visualized the red and green fluorescent reporters associated with the Nesp3mRFP1 or RANGAP1GFP constructs, respectively. Figure 2c shows a field of differentiated 3T3-L1 adipocytes nucleofected with ADNp::SUN1mRFP1Flag and photographed for the red fluorescence of mRFP1 portion of the fusion protein, green fluorescence of neutral lipids stained with Lipotox Green, and the blue fluorescence of DNA stained with DAPI. Nucleofection of 3T3-L1 preadipocytes is very efficient and after a few days of G418 enrichment for transfected preadipocytes nearly every nucleus in the field ( $90 \%)$ of MAs showed associated mRFP1 expression. We found the red fluorescence of nuclei from SUN1mRFP1Flag was not symmetrically distributed over the surface of nuclei and was often skewed to one side relative to DAPI staining of DNA (Fig. 2b). Based on these promising results we focused on the ADNp::SUN1mRFP1Flag construct.

\section{Capture of adipocyte nuclei}

The asymmetric distribution of the nuclear tag should not confound our ability to capture nuclei. Nuclei were purified from mature 3T3-L1 adipocytes 14 days after initiating the differentiation following the protocol outlined in Additional file 8: Figure S7A. Figure 2d shows nuclei captured with anti-RFP rabbit pAb antibody coupled to protein G paramagnetic Dynabeads. Nearly all the mature 3T3-L1 adipocyte nuclei were captured. A

Table 1 Four constructs were tested for fluorescent reporter expression during the differentiation of 3T3-L1 preadipocytes

\begin{tabular}{|c|c|c|c|c|c|c|}
\hline${ }^{\mathrm{a} A D N p:: \text { promoted reporter protein }}$ & Day 4 & Day 5 & Day 6 & Day 7 & Day 10 & Day 14 \\
\hline mRFP1 & + & ++ & +++ & +++ & +++ & +++ \\
\hline SUN1mRFP1Flag & ND & ND & ND & + & +++ & +++ \\
\hline Nesp3mRFP1 & ND & ND & ND & ND & ND & + \\
\hline Nesp3mRFP1Nesp & ND & ND & ND & + & ++ & ++ \\
\hline RANGAP1GFP & ND & ND & ND & ND & + & ++ \\
\hline
\end{tabular}

ND not detected. Standard

${ }^{a}$ The time (days) after induction to differentiate into MAs when the fluorescent protein was detected is indicated. Preadipocytes were nucleofected with five adiponectin promoted reporters, one for cytoplasmic expression (mRFP1) to test the vector pADNpcDNA3.1 KanR and four others targeting nuclei and designed to implement INTACT technology 


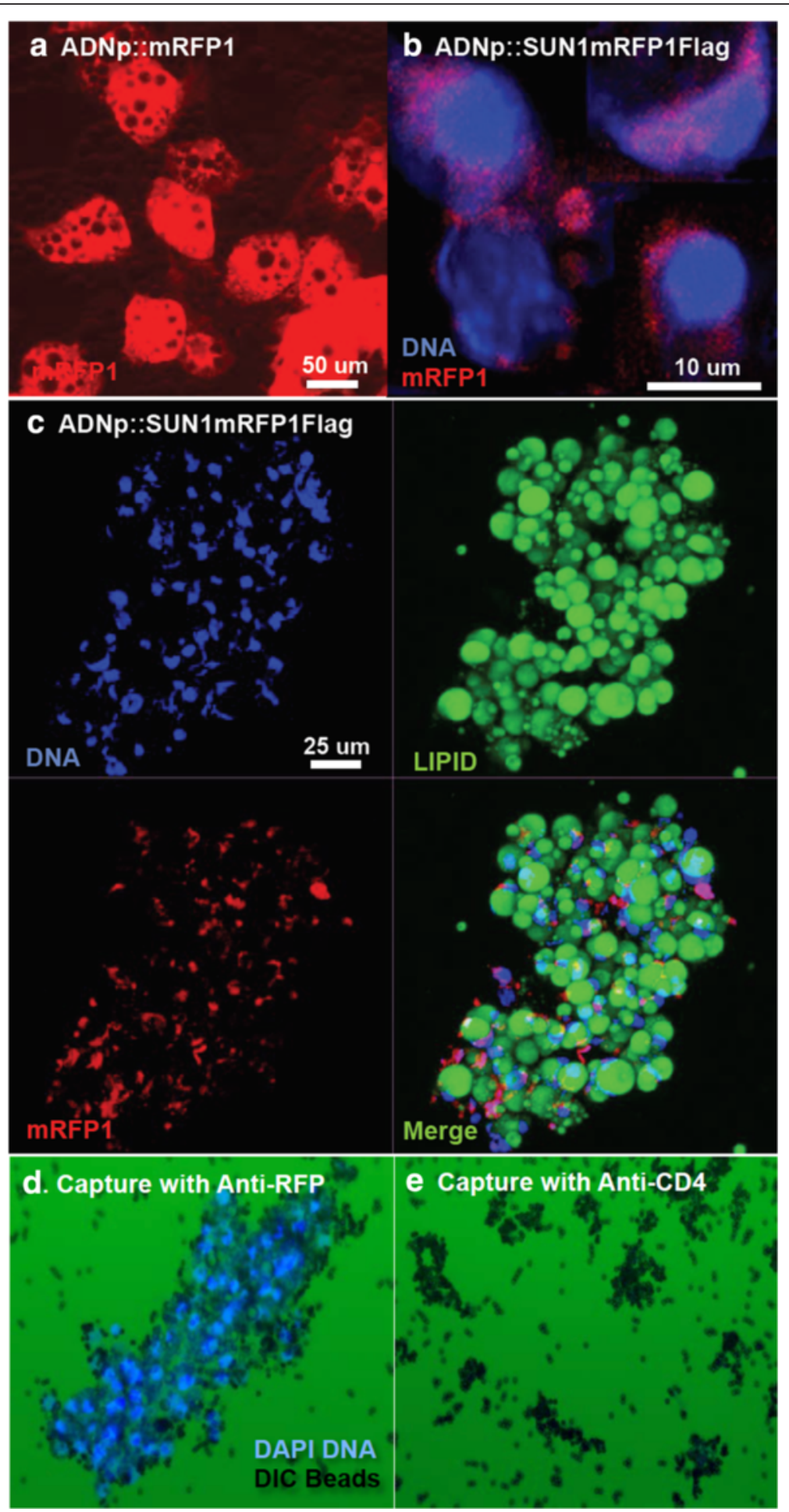

Fig. 2 (See legend on next page.) 


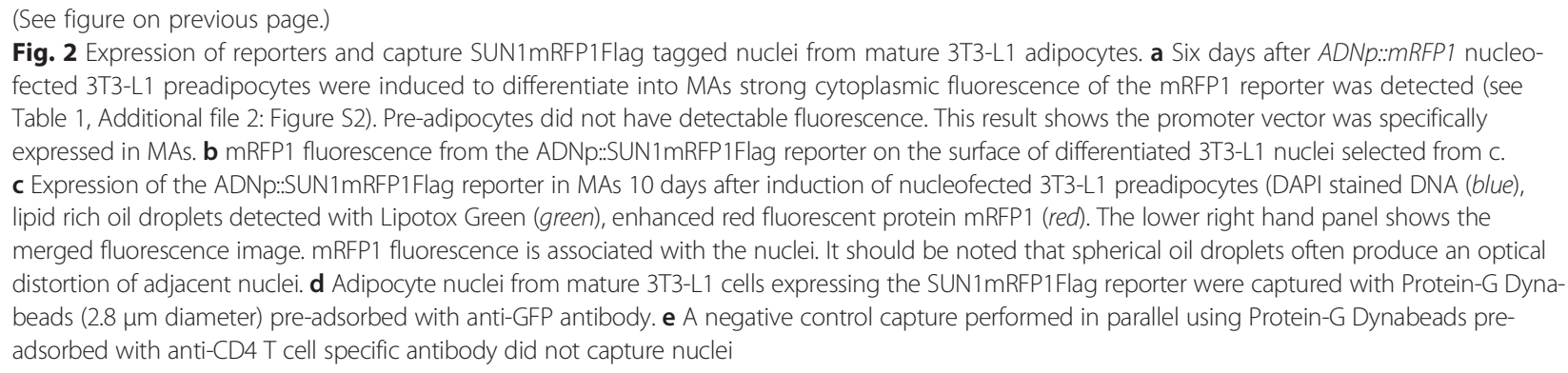

negative control performed with Anti-CD4 antibody did not capture a significant number of nuclei (Fig. 2e), nor did other unrelated antibodies. Subsequent assays with commercial anti-Flag mouse monoclonal antibody and anti-mRFP1 rabbit polyclonal antibodies prepared later for this study both efficiently captured tagged 3T3-L1 adipocyte nuclei (not shown). Although the efficiency of capture was not quantified in detail, we did not detect any obvious difference in the capture with the three antigen tag-specific antibodies tested (anti-GFP, antimRFP1, anti-Flag), suggesting that the nuclear immunocapture technology is relatively robust.

\section{Capturing MA nuclei from transgenic MA-INTACT mice}

MA-INTACT transgenic C57BL/6 mice were generated expressing the ADNp::SUN1mRFP1Flag transgene and the SUN1mRFP1Flag reporter in VAT, SAT, and BAT (see Materials and Methods). Two independent lines of mice, MA-INTACT-C and MA-INTACT-D derived from independent transformation events were developed. The $\mathrm{C}$ and $\mathrm{D}$ lines were indistinguishable from C57BL/6 mice in size and longevity. The breeding of these lines is described in Additional file 7: Figure S8. Three- to four-month-old MA-INTACT mice were sacrificed. Retroperitoneal (RP) and epididymal (EP) VAT, inguinal SAT, and scapular BAT (Fig. 3) were harvested. The tissues were immediately fixed in formalin to preserve chromatin structures, and nuclei were prepared as described in Materials and Methods and Additional file 8: Figure S7. Combined DIC and fluorescence microscopy of DAPI stained nuclei show these nuclear preparations were relatively free of contamination with cell debris (Figure S7C). Furthermore, Western blots immunostained for histone $\mathrm{H} 3$ showed that nuclei prepared from BAT, SAT, and VAT were highly enriched for this nuclear protein, relative to the amount of $\mathrm{H} 3$ in total protein extracts from these three tissues (Figure S7D).

The reporter tagged subsets of MA nuclei (MVA, MSA, and MBA) nuclei were captured using antimRFP1 rabbit polyclonal antibody pre-bound to protein G Dynabeads (Fig. 3b-e). The Western immune-blot probed with antibody to mRFP1 in Fig. 3f shows that
$131 \mathrm{kDa}$ SUN1mRFP1Flag fusion protein was associated with captured MA nuclei in mouse VAT, SAT, and BAT, but not with uncaptured nuclei. It appears a small amount of approximately $25 \mathrm{kDa}$ mRFP1-immunoreactive protein the same size as mRFP1 itself (Right side of blot) may have been released by proteolytic degredation. Yields of nuclei from tissue and captured nuclei from 3-month-old mice are reported in Table 2 . In repeated experiments approximately $45 \%, 50 \%$, and $64 \%$ of the total nuclei were captured from SAT, VAT, and BAT, respectively (Table 2). Similar proportions of adipocyte nuclei were captured from 7-month-old mice.

\section{Gene expression in captured SAT and VAT nuclei}

We quantified transcript levels in cDNA prepared from nuclear RNA from SAT and VAT using qRT-PCR analysis. It is worth mentioning at this point that nuclear transcript levels strongly correlate with cytoplasmic mRNA levels for the vast majority of transcripts [28].

\section{Transcripts enriched in adipocyte and non-adipocyte cell types in SAT and VAT}

The full names of marker transcripts are given in Abbreviations. $S D H A$ was determined to be nearly equivalently expressed among captured (MSA, MVA) and uncaptured (Uncap) SAT and VAT nuclear RNA preparations based on equivalent cDNA input into qRT-PCR reactions, and therefore, SDHA was used as the endogenous control and set to one in calculations of Relative Quantity (see Materials and Methods. The RP and EP VAT RNA preparations from individual mice were combined to increase the amount of VAT RNA and simplify the analysis. While few marker transcripts are absolutely specific for a single cell type, transcripts expected to be highly enriched in mature white adipocytes relative to preadipocytes, leukocytes and/or endothelial cells were assayed first. Captured MSA and/or MVA nuclei expressed 10to 10,000-fold higher levels of $A D I P O Q, P P A R g 2, F A B P 4$, $L E P$, and $E D N R B$ transcripts, relative to Uncap-SAT and Uncap-VAT nuclei (Fig. 4a, $p<0.01$ or 0.001 ). FABP4 is expressed at low levels in leukocytes [65]. Therefore, FABP4 expression in uncaptured leukocyte nuclei may account for this marker transcript being the least 


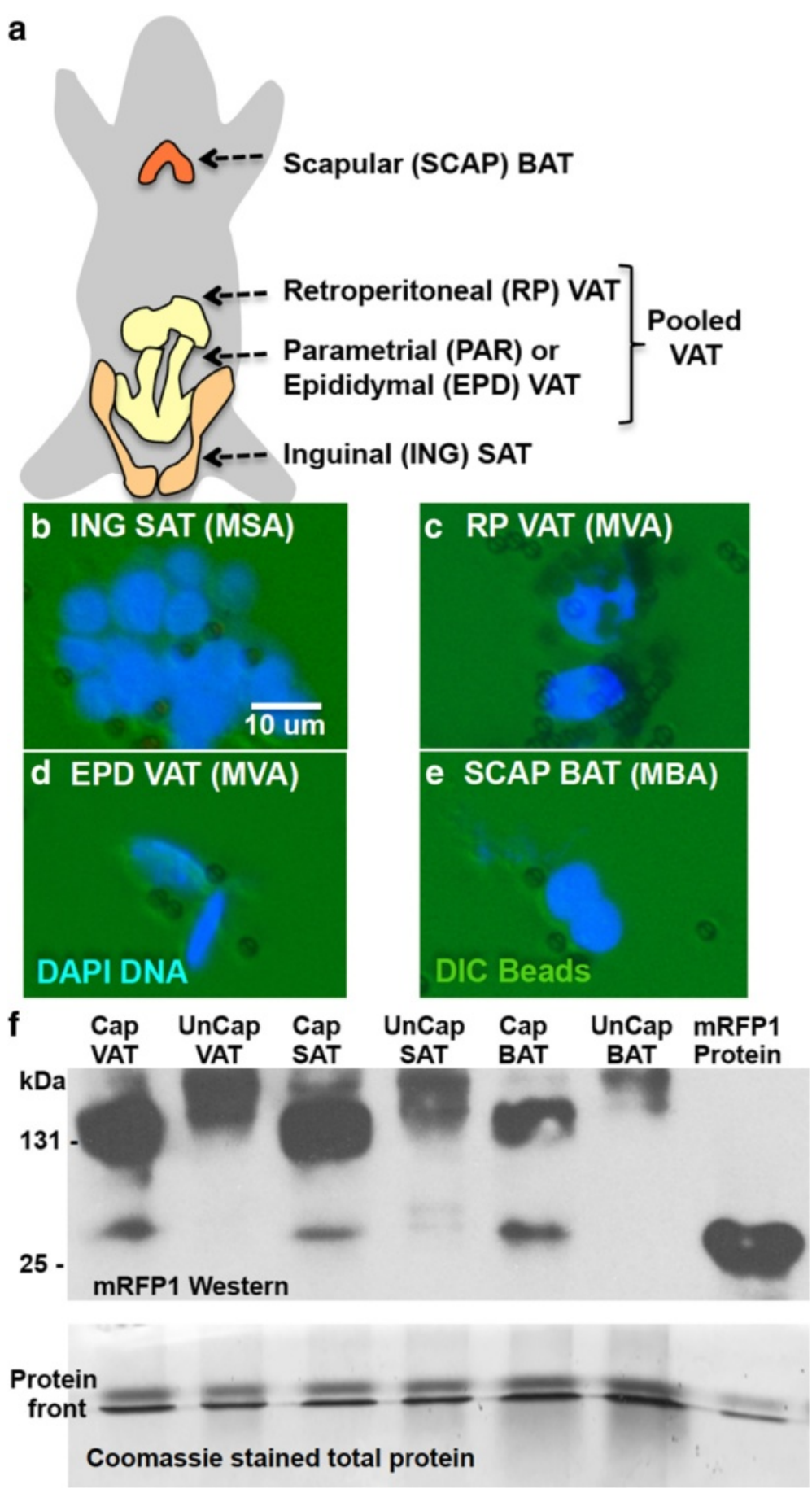

Fig. 3 Mature MA-INTACT mouse adipocyte nuclei expressed SUN1mRFPIFlag RNA in BAT, VAT, and SAT allowing adipocyte nuclei to be captured on Immuno-paramagnetic beads. a Illustration of mouse fat deposits examined. b, c, d, e. Nuclei were efficiently captured from crude nuclear preparations prepared from inguinal SAT (b) retroperitioneal VAT (c) epididymal VAT (d) and scapular BAT (e). Protein G Dynabeads pre-adsorbed to rabbit anti-mRFP1 polyclonal antibody were used in these capture experiments. The clumping of nuclei occurs during successive rounds of washing and capture. Negative control antibodies did not capture significant numbers of nuclei (not shown). f A Western blot (top panel) showed that preparations of captured VAT, SAT, and BAT nuclei expressed the $131 \mathrm{kDa}$ SUN1mRFP1Flag reporter protein, while uncaptured nuclei did not. In house prepared anti-mRFP1 rabbit pAb detected the mRFP1 domain. Purified $25 \mathrm{kDa}$ mRFP1 was run as a positive control. A loading control (bottom panel) showed the approximately equal loading of nuclear proteins and an mRFP1 standard. The loading control samples were run for a short time (20 min) on an SDS PAGE system and protein front stained with Coomassie 
Table 2 Recovery of adipocyte nuclei captured on immuno-paramagnetic beads from VAT, SAT, and BAT dissected from the MAINTACT mouse

\begin{tabular}{llll}
\hline Tissue & Tissue weight (ave.) & \# nuclei recovered (ave.)/nuclei/mg & \# adipocyte nuclei captured ave. $/ \%$ of total \\
\hline VAT & $370 \pm \mathrm{mg}$ & $93,000 \pm / 251 \pm$ & $41,000 / 44.8 \pm 6 \%$ \\
SAT & $160 \pm \mathrm{mg}$ & $94,000 \pm / 587 \pm$ & $48,000 / 49.5 \pm 3 \%$ \\
BAT & $85 \pm \mathrm{mg}$ & $44,000 \pm / 518 \pm$ & $30,000 / 63.5 \pm 8 \%$ \\
\hline
\end{tabular}

${ }^{a}$ Standard errors computed from 5 capture experiments on 5 separate 3-month-old MA-INTACT mice using rabbit anti-mRFP1 polyclonal antibodies on 2.8 micron protein-G coupled paramagnetic Dynabeads. Similar, results were obtained when anti-RFP and anti-Flag antibodies were used as capture reagents

enriched in the captured adipocyte nuclei. Transcripts encoding the adipocyte marker FAM132A (adipolin) were significantly $(p<0.001)$ more highly expressed in Cap-VAT nuclei than Uncap-VAT, but there was no difference between the two fractions of SAT nuclei (Fig. 4b). Hence, it appears that nuclear capture, based on expression of the SUN1mRFP1Flag reporter, efficiently enriches for MA nuclei. Second, transcripts with specificity for non-adipocyte cell types were assayed. Uncap VAT and/or Uncap-SAT expressed 2- to 100-fold higher levels of transcripts encoding most factors with specificity for leukocytes (IKZF1, RETN, ILF3), endothelial cells (RETN, SERPINE1 (PAI1), SERPINF1 (PEDF), TNFA, CD144), and progenitor cells (CD34, KLF2) relative to the levels in Cap-MSA and Cap-MVA nuclei (Fig. 4b, c, d). The majority of these differences were statistically significant $(p<0.01$ or $p<0.001)$. In short, the Uncap-SAT and -VAT nuclear fractions appear to represent the expected enrichment of a mixture of non-adipocyte cell types. However, inconsistent with these data, the endothelial marker transcripts ET1, VEGFA and CD144, the leukocyte marker IFL3, and the progenitor cell markers $I H H$ and $K L F 2$ were found at 2- to 10-fold higher levels in Cap-MVA nuclear fraction rather than Uncap-VAT fraction $(p<0.05$ to $p<0.001)$.

\section{Distinctions between captured MSA and MVA nuclei}

Comparsions of the SAT and VAT transcriptomes from normal and/or obese subjects reveal the coexpression of approximately $90 \%$ of transcripts identified and distinct expression of a remaining substantial subset $[10,66,67]$. We found that captured adipocyte nuclei from VAT and SAT (MVA and MSA nuclei) expressed similar levels of 31 of the 39 transcripts we assayed, but significantly differentially expressed the other eight (e.g., CEBPA, ILF3, KLF2, RETN, SERPINF1, SERPINE1, TDG, TNFA) (Figs. 4 and 5). CEBPA, KLF2, RETN, SERPINE1 and TNFA have reported activities particular to adipocytes or obesityrelated diseases. CEBPA is a transcription factor that assists with the differentiation of adipocytes [68]. We found $40 \%$ lower levels of CEBPA in MVA than MSA nuclei $(p<0.001)$, similar to the results reported in a comparison of VAT and SAT mRNAs in relatively healthy obese men [66]. This same previous study showed higher levels of VEGF and LEP in VAT than SAT, but we did not observe such differences between MVA and MSA nuclear RNAs. KLF2 acts to suppress adipogenesis [69]. Thus, the two-fold higher levels of KLF2 we found in MVA nuclei relative to MSA nuclei $(p<0.01)$ may reduce the relative levels of adipogenesis in VAT. TNFA is a cytokine secreted by macrophages linked to insulin resistance and diabetes that is also known to activate preadipocyte genes and inhibit adipogenesis [70, 71]. Most studies examine adipocytes exposed to exogenous TNFA, yet we observed substantial expression of endogenous TNFA transcripts in both MVA and MSA nuclei. Further, MVAs expressed several times more TNFA than MSAs $(p<0.01)$, again favoring reduced adipogenesis in VAT. Hence, differences in CEBPA, KLF2 and TNFA transcripts all favor reduced adipogenesis VAT relative to SAT. We likely detected and resolved the differential expression of these genes between MSAs and MVAs, because their expression levels were not assayed among the transcripts in mixture of other adipose tissue cell types $[10,66,67]$.

A few other transcripts differentially expressed in MVAs and MSAs may be linked to obesity health risk. Serum levels of the adipokine RETN (resistin) positively correlate with mortality risk from diabetes and cardiovascular disease [72, 73]. Captured MVA nuclei expressed 40-fold higher levels of RETN transcripts than MSA nuclei $(p<0.001)$. Serpins are protease inhibitors that unfold and lead to the degradation of their target proteases, and hence, play important roles in inflammation and cell death. A systems biology network analysis of the plasma proteome expressed in obese diabetic patients relative to normal healthy subjects found SERPINE1 at more central nodes of networks linked to other proteins with roles in obesity, diabetes, and cardiovascular disease, than any other plasma protein [74]. Transcripts for SERPINE1 and its distant sequence homolog SERPINF1 were 20-fold and five-fold, respectively, more highly expressed in MVA than MSA nuclei $(p<0.01)$. These transcript differences support the potential negative health outcome of having excess VAT.

Considering that little is known about the differentiation of white adipocytes into beige adipocytes within SAT and VAT, we assayed two factors normally associated the browning of adipose tissue and heat generating 

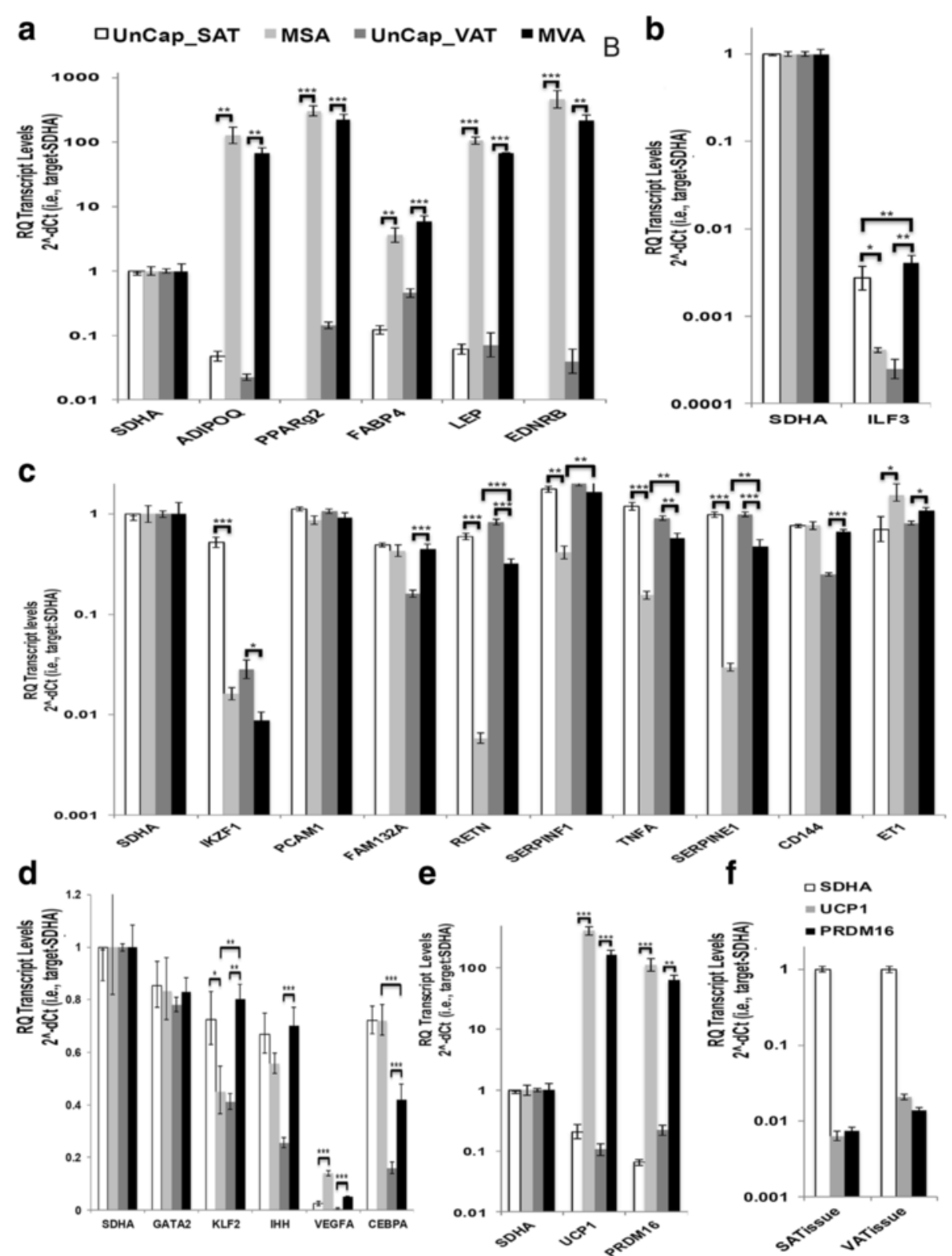

Fig. 4 Expression of cell-type specific transcripts in MA nuclei captured from VAT and SAT. qRT-PCR analysis was performed on cDNA prepared from captured adipocyte nuclei from VAT (MVA) and SAT (MSA) and uncaptured nuclei (UnCap-VAT and -SAT). Nuclear mRNAs were assayed for transcripts encoding (a) MA markers, (b, c, d) potential markers for leukocytes, endothelial cells, and progenitor cells, (e) markers of thermogenic beige/bright adipocytes. $\mathbf{f}$ The levels of PRDM16 and UCP1 transcripts in whole VAT and SAT tissue were also assayed. SDHA was used as the endogenous control as it was nearly equivalently expressed in all samples relative to the amount of input CDNA. Bar graphs show the Mean \pm SEM with $p<0.05^{*}, p<0.01^{* *}, p<0.001{ }^{* * *}$ indicated for selected comparisons

activity (Fig. 4e). PRDM16 is a transcription factor essential to brown/beige adipose tissue development and UCP1 is a nuclear encoded uncoupling protein 1 that generates heat in the mitochondria of brown and beige adipocytes. PRDM16 and UCP1 transcripts were significantly upregulated (200- to 1,000-fold) in Cap-MSA and Cap-MVA nuclei compared to uncaptured nuclei $(p<0.01$ or 0.001 ) and 10,000-fold higher than they were expressed in their parent SAT and VAT tissues (Fig. 4f).

\section{Captured BAT nuclei}

SUN1mRFP1Flag tagged nuclei were captured from BAT as shown in Fig. 3f and quantified in Table 2. However, adiponectin (ADIPOQ) expression suppresses the thermogenic 


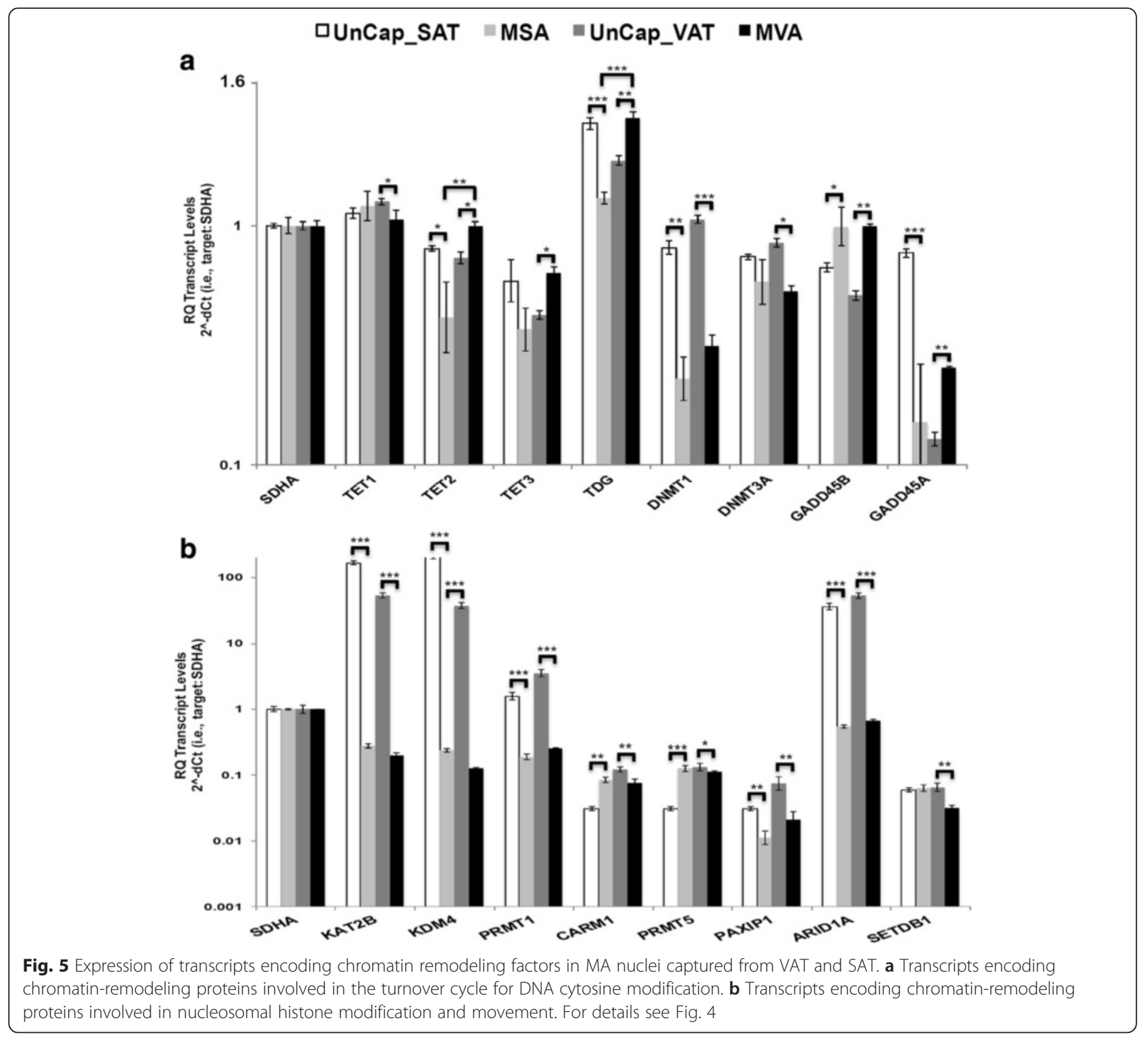

program in brown adipocytes [61] and reduces expression of UCP1, the main uncoupling protein that generates heat in brown adipocytes. Therefore, the ADIPOQ promoter driven reporter ADNp::SUNmRFP1Flag is not appropriate to tag thermogenic brown adipocytes. The results from our assaying a battery of cell type-specific and function-specific transcripts by qRT-PCR (Additional file 10: Figure S9) do not identify the captured nuclei as representing a single recognizable cell type. As might be expected from the inverse relationship between $A D I P O Q$ and $U C P 1$, uncaptured BAT nuclei expressed several fold higher levels of transcripts encoding UCP1 and APLN[75] $(p<0.01)$, when compared to captured BAT adipocyte nuclei. APL is an adipocyte specific hormone that promotes the metabolic activity of brown adipocytes [75]. By contrast, captured MBA nuclei were enriched for some adipocyte enriched marker transcripts FAM132A (adipolin), LEP [76], PAX3 [77] RETN, and SERPINF1 [78] $(p<0.05$ to 0.001), while neither nuclear population was enriched for other transcripts that might be considered adipocyteenriched (e.g., PRDM16, PPARg2, FABP4, ZIC1). In addition, captured BAT nuclei were enriched for progenitor cell transcripts CD34, GATA2, KLF2, and $I H H(p<0.05$ to 0.01$)$. Finally, and adding to the complexity of this result, endogenous ADIPOQ transcripts were equivalently expressed in captured and uncaptured nuclei. We speculate that the ADIPOQ promoter driven reporter tagged multiple cell types in BAT. 


\section{Transcripts encoding chromatin remodeling proteins}

We assayed transcript encoding two classes of chromatin remodeling factors. First, we examined mRNAs for factors involved in the cycle of DNA cytosine modification and turnover, because of their role in adipogenesis. DNA cytosine methylation in preadipocytes during the contact inhibition stage of growth appears essential to licensing their ability to differentiate at a later stage into mature lipid containing adipocytes [79]. During the execution of adipogenesis cytosine demethylation of PPARg2 promoter is essential for PPARg2 expression [80]. By contrast, the gene for the bromodomain suppressor of adipogenesis BDR2 becomes increasingly methylated and silenced during adipogenesis [81]. Our analysis included two DNA cytosine methyltransferases DNMT1 and DNMT3A that methylate cytosine (C) to 5methylctosine $(5 \mathrm{mC})$, three $5 \mathrm{mC}$ dioxygenases (TET1, 2, 3 ) that oxidize $5 \mathrm{mC}$ to 5 -hydroxymethylcytosine $(5 \mathrm{hmC})$ and subsequently to more oxidized forms $(5 \mathrm{caC}$ and $5 \mathrm{fC}$ ), thymine glycosylase TDG that removes $5 \mathrm{caC}$ and $5 \mathrm{fC}$ to generate an abasic site, and repair enzymes $G A D D 45 A$ and $G A D D 45 B$ that restore $C$ residues to the abasic sites (Fig. 5a). TET2, TET3, TDG, GADD45A and GADD $45 B$ transcripts were at higher levels in Cap-MVA nuclei than Uncap-VAT nuclei $(p<0.05$ to 0.01$)$. The encoded proteins are all involved in removal of $5 \mathrm{mC}$ and cycling back to $\mathrm{C}$, suggesting that the cycle of cytosine modification might run faster in VAT-derived adipocytes. In contrast, TET2, TDG, DNMT1, and GADD45A transcripts were at higher levels in Uncap-SAT than Cap-MSA nuclei $(p<0.05$ to 0001). TDG (thymine DNA deglycosidase) participates in the turnover of DNA 5'methylcytosine and in the repair of DNA in terminally differentiated cells. TDG is expressed in human adipose tissue derived mesenchymal stem cells and [82]. Its 4fold higher expression in MVA than MSA nuclei might represent regulatory or repair functions. In short the transcript expression for factors involved in cytosine modification and turnover are distinctly differentially expressed in SAT- and VAT-derived nuclear populations, which should impact adipogenesis.

Second, we examined factors involved histone and nucleosome remodeling, focusing on the posttranslational modification of histone side chain lysine and arginine residues (Fig. $5 \mathrm{~b}$ ), because of their roles in adipogenesis [83-85]. Transcripts encoding the lysine acetyltransferase $K A T 2 B$ and lysine demethylase $K D M 4$ are expressed at 100- to 1,000-fold higher levels in Uncap-SAT and -VAT nuclei than in the captured fractions. Transcripts for the protein arginine methyltransferase PRMT1 were expressed at 8- to 10-fold higher levels in Uncap-SAT and Uncap-VAT nuclei than in captured. Two other PRMTs, CARM1 (PRMT4) and PRMT5 were 2- to 3fold more weakly expressed in Uncap-SAT nuclei than in the other three nuclear fractions. Transcripts for PAXP1 which controls chromatin condensation and gene activation and ARID1A (BAF250) a ATP-dependent swi/snf remodeler were 3- to 50-fold more highly expressed in Uncap-SAT and -VAT nuclei than CapMSA or Cap-MVA nuclei. In total, the generally higher expression of these transcripts in non-adipocyte nuclei suggest that the non-adipocyte cell types may be turning over the classes of chromatin structures controlled by these remodeling activities faster than adipocytes.

\section{Discussion}

\section{MAs from SAT and VAT}

Mature adipocyte nuclei expressing the SUN1mRFP1Flag reporter were easily captured from SAT and VAT dissected from the MA-INTACT mouse. Most transcript markers of specific for SAT and VAT MAs were expressed at three orders-of-magnitude higher levels in the captured nuclei relative to uncaptured nuclei. This demonstrates not only the exceptional purity of captured nuclei, but also the efficiency of capture, because few nuclei with these activities appear to be left behind in the uncaptured fraction. Similarly, most transcripts specific to leukocyte, endothelial, and progenitor cells were significantly enriched in the uncaptured nuclear fraction. VAT and SAT are relatively distinct in their developmental origins, in their metabolic and gene expression profiles, and in their contribution to obesity related disease [4-10, 86]. So perhaps it is not surprising that a few transcripts considered markers of adipocytes or nonadipocytes were found significantly enriched in the captured MVAs as compared to the uncaptured VAT and/or captured MSA nuclei. We found captured, MVAs expressed significantly higher levels of TNFA, CEBPA, and KLF2 transcripts than MSA, all of which favor reduced levels of adipogenesis in VAT and higher levels of RETN and SERPINs, which are linked to obesity-related disease risk. Most of these differences between VAT and SAT have not been reported previously, presumably due to the power of examining mature adipocyte nuclei enriched away from other adipose tissue cell types. As additional explanations for transcripts being unexpectedly enriched in the MVA fractions we suggest: (1) MAs isolated from within their in vivo environment may have heretofore unknown properties distinct from adipocytes matured in silico and/or (2) nuclear RNA levels do not represent cytoplasmic RNA levels for a small percent of transcripts [28].

By contrast, both captured and uncaptured nuclei from BAT were slightly but significantly enriched for some classes of marker transcripts, but they expressed the same levels of endogenous $A D I P O Q$ transcripts. We 
anticipated that the $A D I P O Q$ promoter driven reporter would not tag thermogenic adipocyte nuclei [61], but in any case, a large percentage of BAT nuclei were captured (Table 2). Our data suggest that expression of the ADNp::SUNmRFP1Flag reporter is not cell type specific in BAT. Perhaps endogenous transcription factors and/ or transgene position effects alter reporter expression in BAT, problems that do not appear to impact reporter specificity in VAT or SAT.

White adipocyte-derived beige/bright adipocytes within white adipose tissue may behave as thermogenic adipocytes and express PRDM16, a high level transcriptional co-regulator of brown adipocyte development, and the heat generating uncoupling protein UCP1 [21, 87, 88]. However, it was surprising to find the captured MSA and MVA nuclei expressed such exceptionally high levels of nuclear transcripts encoding PRDM16 and UCP1, three orders of magnitude above the levels in non-adipocyte nuclei and above that observed in the adipose tissues themselves and above the endogenous control SDHA. It is unlikely that there were enough of the beige adipocytes enriched in the MSA and MVA nuclear fractions to account for such high transcript levels. Further, ADIPOQ expression is known to suppress UCP1 expression in brown adipocytes [61]. An alternative explanation is that these two transcripts are exceptions to the rule about nuclear transcript levels correlating with cytoplasmic transcripts levels. In the founding paper on INTACT technology [28], there was a strong linear correlation between nuclear and cytoplasmic mRNA levels with an $r$ value of 0.94 . In other words, only a small fraction of transcripts do not fit this relationship. Yet, PRDM16 and UCP1 transcripts could belong to this subset, and be much more highly expressed in the nucleoplasm than the cytoplasm. If these transcripts remain in the nucleus in most tissue-derived adipocytes, they would not be expressed as protein. If this is the case, then nuclear RNA transport may be an important factor controlling UCP1 and PRDM16 expression in adipocytes. The ongoing transcription and nuclear accumulation of thermogenic transcripts in MAs might create a poised decondensed chromatin state enabling white adipocytes to more rapidly develop into beige adipocytes upon cold induction $[89,90]$.

\section{Chromatin remodeling factors in SAT- and VAT-derived adipocytes}

Because adipocytes are the defining cell type in adipose tissue, we had considered the following hypothesis: adipocytes isolated from VAT and SAT express higher levels of transcripts for chromatin remodeling factors than supporting cell types, perhaps making them more responsive to environmental stimuli. We examined factors involved in DNA cytosine modification and nucleosomal histone side chain modification that could be involved in controlling adipogenesis or maintenance of MAs.

\section{DNA cytosine modification in adipose tissue}

The development of lipid body-rich MAs proceeds after preadipocytes leave the cell cycle [79] and a complex role for DNA methylation-based gene silencing by has been implicated in this process. Global DNA cytosine methylation levels increase, two days after the differentiation of 3 T3-L1 cells begins [79]. Within the first $24 \mathrm{~h}$ of differentiation, expression of the maintenance DNA methyltransferase DNMT1 increases significantly [91]. Once MAs have developed DNMT1 levels decrease. The de novo cytosine methyltransferase DNMT3A may also play a positive role, because siRNA silencing of DNMT3A in 3 T3-LI preadipoctyes significantly blocks adipogenesis [79]. When a cytidine analog and inhibitor of both DNMTs 5-azacytidine (5$\mathrm{azaC}$ ) is used to treat bone marrow derived MSCs, a normal precursor of adipocytes, there is a decrease in precursor cell proliferation and adipogenesis [92]. Similarly, treating atrial cardiac cells with 5 -azaC leads to the trans-differentiation into lipid body-containing adipocytes [93]. In contrast to these experimental results suggesting a simple positive role for methylation, siRNA silencing of DNMT1 in preadipocytes accelerates adipogenesis [91]. To understand the role of DNA methylation it is useful to place these results in a larger context. DNA cytosine modification at critical gene region CG dinucleotides proceeds via a complex cycle of methylation to $5 \mathrm{mC}$ by DNMTs, oxidation to $5 \mathrm{hmC}$ and beyond by TETs, and base excision and repair by TDG, GADD45s, and additional factors. Although steady state levels and gene region distribution of $5 \mathrm{mC}$ often appear constant within a cell type, the turnover rate of $5 \mathrm{mC}$ has been shown to be quite rapid when measured. Half lives of less than 30 min are not uncommon [94]. Any step in the cycle might be differentially regulated in a particular cell type. Therefore we thought it would be informative to assay representative factors spanning the cytosine modification cycle. Although it is true that we found differential expression of 7 of the 8 factors assayed among one or more of the captured adipocyte nuclei or uncaptured non-adipocyte nuclear fractions, the results do not support our working hypothesis. As particular examples, TDG, DNMT1, and GADD45A transcripts are much more highly expressed in uncaptured non-adipocyte SAT nuclei than in MSA nuclei. Only TET3, TDG, and GADD 45A were more highly expressed in MVA nuclei than uncaptured non-adipocyte VAT nuclei fitting the prediction from our hypothesis. 


\section{Nucleosomal histone modification}

We examined the expression of transcripts encoding several nucleosomal histone remodeling factors with presumed roles in adipogenesis or maintenance of adipocytes.

Very early in the differentiation of 3T3-L1 preadipocytes levels of histone 3 lysine 9 methylation (H3K9me3) increase 2- to 3-fold, enabling preadiopcytes to differentiate into MAs [79]. SETDB1 and KDM4 regulate the levels of histone methylation (e.g., H3K9me1, me2, me3). SETDB1 methylates H3K9 and H3K9me1 to H3K9me3, a modification associated with transcriptional repression [95]. PPARg is a high-level regulator of adipogenesis, fatty acid storage and glucose metabolism. Via its modifying activity SETDB1 represses PPARg transactivation at target genes. In opposition to SETDB1, KDM4A/JMJD2A is a lysine-specific demethylase that directly demethylates H3K9me3 to H3K9me1/2 [96, 97]. KDM4A is essential to recruiting PPARg to its target genes expressed during adipocyte development [98]. The levels of SETDB1 were not distinct among the nuclear fractions. Somewhat surprising, we found order of magnitude higher levels of KDM4 in the two uncaptured SAT and VAT nuclear populations, relative to levels the captured MSA and MVA fractions. Again these data are contrary to our working hypothesis.

We examined the transcript levels of three histone arginine methyltransferases (PRMTs), PRMT1, CARM1 (PRMT4) and PRMT5. Among their multiple activities these three PRMTs can methylate four arginine residues on the $\mathrm{N}$ terminus of histone $\mathrm{H} 3$ and one on $\mathrm{H} 4$ and these modifications are generally associated with gene activation. PRMT4 and PRMT5 appear to play positive roles in adipogenesis by supporting PPARg expression [85, 99-101]. PRMT1 is the dominant type I PRMT and has an essential role in cell proliferation and genome maintenance [102] and defects in PRMT1 are associated with cardiovascular disease [103, 104]. However, specific roles for PRMT1 in preadipoctyes, MAs, or adipogenesis are yet to be described. We found PRMT1 was several fold more highly expressed in VAT and SAT non-adipocyte nuclei, than in captured MSA or MVA nuclei. This may not be surprising considering that PRMT1 appears to be important for the mesenchymal-epithelial transition, which might impact the endothelial cell population. The levels of CARM1 and PRMT5 transcripts fit expectation, at least in part, because their levels were a few-fold higher in captured MSA nuclei than in uncaptured SAT nuclei. ARID1A (BAF250) is the well-studied ATPdependent swi/snf subunit of several nucleosome remodeling complexes. ARID1A transcripts were dramatically more highly expressed in the uncaptured fractions.

In summary, among captured MSA and/or MVA nuclei and uncaptured nuclei, there were distinct differences in the expression levels of 10 of the 16 transcripts examined.
However, the results do not support the hypothesis being tested. In fact, for a significant majority of comparisons between captured MSAs and MVAs and their uncaptured counterparts, the uncaptured nuclei expressed higher levels of the chromatin remodelers assayed. Considering the evidence for the high degree of purity of captured MA nuclei, it is unlikely that our results reflect any significant contamination of the captured and uncaptured fractions from SAT or VAT. Although a simple interpretation is not obvious, these results do suggest that the supporting cell types within SAT and VAT are more active in chromatin remodeling than MAs.

\section{Conclusions}

Epigenetics is the study of cell-type specific differences in chromatin structure within an organ or tissue developmental context. To improve cell-type specific analyses of adipocytes we engineered two populations of inbred MAINTACT mice in which the surface of MA ADIPOQ expressing nuclei are tagged. This enabled the efficient immunocapture of MSA and MVA nuclei from within VAT and SAT, separating them from the nuclei of contaminating endothelial, leukocyte, progenitor, and preadipocyte nuclear types. Transcript for classical adipocyte markers were enriched in the captured nuclei by several orders of magnitude, confirming the high levels of purity of MSA and MVA nuclei. Captured and uncaptured nuclei, however, had some novel and unexpected properties. For example, MSA and MVA nuclei expressed high levels of transcripts for two markers of thermogenic beige or brown adipocytes. In addition, the uncaptured populations often expressed higher levels of transcripts encoding chromatin remodeling factors assayed, relative to captured adipocyte nuclei. These data do not support our working hypothesis that adipocytes would be the most epigenetically active cell type in adipose tissue.

MA-INTACT mice may be used to monitor epigenomic, transcriptomic, and proteomic changes in isolated MA nuclei from VAT and SAT and perhaps other tissues that we have not yet examined such as adipocytes within bone and muscle. Our long-term goal was to enable studies on the impact of various environmental influences such as aging, diet, exercise, stress, and drug treatment on adipocytes. The reporter transgene ADNp::SUN1mRFP1Flag could be recombined with model mice designed to examine obesity-related diseases in which adipocytes may play direct or indirect roles such as metabolic syndrome, cardiovascular disease, some cancers, Alzheimer's, and diabetes.

The D line of MA-INTACT mice, homozygous for the ADNp::SUN1mRFP1Flag transgene (Additional file 7: Figure S8D) and will be made available for distribution after publication of this manuscript. 


\section{Additional files}

Additional file 1: Figure S1. Structure of the ADIPOQ expression vector pADNpcDNA3.1 KanR. The indicated multilinker contains a BspLU11/ site (5'-ACATGT) containing the ATG initiation codon and the down stream Nhel site forming the replacement region used in the molecular cloning of five reporter protein coding sequences. (PDF $1382 \mathrm{~kb}$ )

Additional file 2: Figure S2. Structure of the ADNp::mRFP1 reporter vector in which the CDS of MRFP1 was cloned into the BspLU11/ - Nhel replacement region of pADNpcDNA3.1. This reporter was used to test the specificity of expression from the ADIPOQ expression cassette. The untethered mRFP1 is expressed in the cytoplasm. (PDF $1382 \mathrm{~kb}$ )

Additional file 3: Figure S3. Structure of the INTACT reporter vector pADNp::SUN1mRFP1Flag. The mRFP1Flag CDS was inserted into the BspLU11I - Nhel replacement region of PADNpcDNA3.1. This was the most powerful reporter construct and was used in most applications described in the manuscript. (PDF $1382 \mathrm{~kb}$ )

Additional file 4: Figure S4. Structure of the INTACT reporter ADNp::mRFP1Nesp. The mRFP1Nesp CDS was inserted into the BspLU11/ Nhel replacement region of pADNpcDNA3.1. This construct was set aside after initial screening in 3 T3-L1 derived adipocytes. (PDF 1382 kb)

Additional file 5: Figure S5. Structure of the INTACT reporter ADNp::NespmRFP1Nesp. The NespmRFP1Nesp CDS was inserted into the BspLU111 - Nhel replacement region PADNpcDNA3.1. This construct was set aside, after initial screening in 3 T3-L1 derived adipocytes. (PDF $1382 \mathrm{~kb})$

Additional file 6: Figure S6. Structure of the INTACT reporter ADNp::RANGAP1GFP-BLRP. The RANGAP1GFP-BLRP CDS was inserted into the BspLU11/ - Nhel replacement region pf pADNpcDNA3.1. BspLU11L and Nhel sites were added to the RanGap1-GFP-BLRP gene described in Deal \& Henikoff [28] by mutagenic PCR. This construct was set aside, after initial screening in 3 T3-L1 derived adipocytes. (PDF 1382 kb)

Additional file 7: Figure S8. Breeding of transgenic mouse lines $\# 0023 C$ (C line) and \#0025D (D line) expressing the ADNp::SUN1mRFP1Flag construct. A. Litter Progression from Founder \#0023 (C line). B. Litter Progression from Founder \#25 (D-line). C \& D. Monitoring transgene expression during backrosses of $C$ and $D$ line to WT. Relative Quantity of transgene (RQ) from qPCR screening of the first generation of selfing of F2 generation offspring to obtain homozygous lines for the ADNp::SUN1mRFP1Flag transgene. An mRFP1 gene primer pair was used (mRFP Additional file 9: Table S1). CT values were normalized to $\mathrm{APCR}$ values for actin gene ACTB using the $\mathrm{dCT}$ method [105] to obtain a relative quantity of gene copies ( $1 \times$ hets, $2 x$ homo, $\sim 0$ WT). D. Notice the constant $2 \times \mathrm{RQ}$ level of MRFP1 qPCR product when inbreeding homozygous lines. (PDF $1382 \mathrm{~kb}$ )

Additional file 8: Figure S7. Enrichment protocol for SAT, VAT, and BAT cellular nuclei images showing relative purity. A. Adipose tissue depots examined. B. Summary of protocol for isolating nuclei prior to capture. C. Image of enriched nuclei from VAT, SAT, and BAT. This is a combined image with DIC in green and DAPI DNA fluorescence in red. D. The protein was extracted from tissue and from enriched nuclear preparations, resolved by PAGE-SDS on a $15 \%$ gel run for $1 \mathrm{hr}$ and $15 \mathrm{~min}$ at $20 \mathrm{ma}$ and examined for the levels of nuclear protein histone $\mathrm{H} 3$ on an immunoblot (anti-H3 mouse monoclonal ab10799). The signal was developed using HRP-conjugated goat anti-mouse antibody (NA931V) and a ECL kit (RPN2106) for detection. Parallel samples were run for $15 \mathrm{~min}$ on a duplicate gel and the protein front was stained for total protein with Coomassie blue to show approximately equal loading among paired samples. (PDF $1382 \mathrm{~kb}$ )

Additional file 9: Table S1. Oligonucleotide primers used during qRT-PCR of transcripts and qPCR of ADNp::SUN1mRFP1Flag transgene. (PDF $1382 \mathrm{~kb}$ )

Additional file 10: Figure S9. Expression of cell-type- and functionspecific transcripts in MA nuclei captured from BAT. qRT-PCR analysis was performed on cDNA prepared from captured adipocyte nuclei from BAT (MBA) and uncaptured nuclei (UnCap-BAT). Nuclear mRNAs were assayed for transcripts encoding (A-F) Cell-type and function markers. SDHA was used as the endogenous control as it was nearly equivalently expressed in captured and uncaptured samples relative to the amount of input CDNA. Bar graphs show the Mean \pm SEM with $p<0.05^{*}, p<0.01 * *, p<0.001 * * *$ indicated for selected comparisons. (PDF $1382 \mathrm{~kb}$ )

\section{Abbreviations}

ADIPOQ, adiponectin; APLN, Apelin; ARID1A (BAF250, SWI-SNF-related AT Rich Interactive Domain 1A); CARM1, PRMT4, Coactivator-Associated Arginine Methyltransferase 1; CEBPA, CCAAT/Enhancer Binding Protein (C/EBP), Alpha; CD144/CDH5, VCAD, Cadherin 5: DNMT1 and DNMT3A, DNA Cytosine-5'Methyltransferase 1 and 3A; EDNRB, Endothelin receptor type B; ET1, ET-1, Endothelin 1; FABP4, adipocyte protein 2, aP2, FABP4, fatty acid binding protein 4; FAM132A, Adpl, Adipolin, Adipose-Derived Insulin-Sensitizing Factor; GADD45A B, Growth Arrest And DNA-Damage-Inducible, Alpha, Beta; GATA2, endothelial transcription factor GATA Binding Protein 2; IKZF1, Ikaros family zinc finger protein 1; KAT2C, MLL3, KMT2C, Lysine-Specific

Methyltransferase 2C; KDM4A, H3K9/36me3 lysine-specific demethylases 4A JMJD2A Jumonji Domain Containing 2A; $1 \mathrm{HH}$, Indian Hedgehog Homolog), IKZF1 (IKAROS family zinc finger protein 1; ILF3, interleukin enhancing binding factor 3; KLF2, zinc finger transcription factor Kruppel-Like Factor 2; LEP, leptin, obesity factor, obesity homolog; SERPINE1, PAI1, Plasminogen activator inhibitor-1; PCAM1, Platelet/Endothelial Cell Adhesion Molecule 1; PPARg2, adipocyte specific $2^{\text {nd }}$ isoform of peroxisome proliferator-activated receptor gamma; PRDM16, PR domain containing 16; PRMT1 and PRMT5, protein arginine methyltransferase 4 and 5; PAXIP1/PTIP, PAX Interacting with TranscriptionActivation Domain Protein 1, promotes histone H3 lysine 4 methylation; RETN, Resistin, C/EBP-Epsilon-Regulated Myeloid-Specific Secreted Cysteine-Rich Protein; SDHA, Succinate dehydrogenase complex subunit A; SERPINE1, PAI1, Endothelial Plasminogen Activator Inhibitor; SERPINF1, PEDF, Pigment epithelium-derived factor; SETDB1/KMT1E, SET Domain Bifurcated 1, Histone H3-K9 Methyltransferase 4; SREBF1, sterol regulatory element binding transcription factor 1; TDG, G/T Mismatch-Specific Thymine DNA Glycosylase; TET1, 2, 3, Ten-Eleven Translocation1, 2, 3, Tet Methylcytosine Dioxygenase, TNFA, tumor necrosis factor alpha, UCP1, uncoupling protein 1; VEGFA, Vascular Endothelial Growth Factor A; ADSC, adipose tissue derived stem cell; DFAT, dedifferentiated adipocyte-derived progeny cell; INTACT, Isolation of Nuclei Tagged in specific Cell Types; MA, mature adipocyte; VAT, SAT, BAT, visceral, subcutaneous, and brown adipose tissue, respectively; MVAs MSAs MBAs, mature adipocytes from VAT, SAT, and BAT, respectively; qRT-PCR, quantitative real-time polymerase chain reaction amplification of CDNA

\section{Acknowledgements}

We wish to thank Mary Anne Della-Fera, Emily Rose England Trunnell, Rhi Biddy, and Colette N. Miller, who offered helpful advice and encouragement as this project and manuscript developed. Early insight into the design of reporter constructs resulted from helpful discussions with Roger Deal at Emory University and Sean Eddy and Gilbert Henry at the HHMI Janelia Farm Research Campus. The MA-INTACT mouse was constructed with the assistance of the Emory University School of Medicine Transgenic Mouse and Gene Targeting Core Facility.

\section{Funding}

This work was funded by grants from the U.S. National Institutes of Health's National Institute of Diabetes and Digestive and Kidney Diseases NIDDK DK096300 and DK100392 and the University of Georgia's Research Foundation's Obesity Initiative to RBM and from Georgia Research Alliance Eminent Scholar Fund to the late Dr. Clifton A. Baile.

\section{Availability of data and materials}

Novel gene and vector sequences were submitted to NCBI GenBank under Banklt1915001 and match the sequences maps given in the data supplement. Their sequence accession numbers are as follows pADNpcDNA3.1 (KX176867), mRFP1 (KX176868), Sun1mRFP1Flag (KX176869), Nesp3-mRFP1-Flag (KX176870), Nesp3mRFP1Nesp (KX176871), and RanGAP-GFP-BLRP (KX176872).

\section{Authors' contributions}

SA performed the majority of experiments with adipocytes and mice including nucleofections, screening of transgenic mice, breeding them, capturing nuclei, preparing DNA and RNA, qRT-PCR of transcripts, and editing the manuscript. PY helped with the breeding of mice, qRT-PCR, and developed the initial isolation 
protocol for adipose tissue nuclei. ECM made all of the vector and gene constructs. MKK helped with microscopy. DH helped with the breeding of mice and selection of an appropriate strain. CAB assisted with the conception and funding of the project. RBM conceived of the project and its experimental design including the sequences of the gene constructs, guided the research, obtained most of the funding, and wrote the manuscript. All authors read and approved the final manuscript.

\section{Authors' information}

SA is a Ph.D. Senior Research Scientist who has worked on obesity-related projects for several years. PY is a masters level senior graduate student and Ph.D. candidate in the Genetics Department at UGA. ECM is a Masters level Research Coordinator with high-level skills in molecular genetics. MKK (Ph.D.) is Director of UGA's Biomedical Microscopy Core, who has collaborated with RBM for 16 years. DH is Program Coordinator for UGA's Obesity Initiative and was a Research Coordinator who collaborated with $C A B$ for 25 years. $C A B$ was the University of Georgia D.W. Brooks Distinguished Professor, Georgia Research Alliance Eminent Scholar in Biotechnology, and Head of UGA's Obesity Initiative, whose recent research focused on the physiology and biochemistry of obesity and bone disorders. RBM is a Distinguished Research Professor in the Genetics Department and a pioneer in the field of molecular genetics, who has worked on problems of cell-type specific epigenetics for the last few years.

\section{Competing interests}

The authors declare that they have no competing interests.

\section{Ethics approval and consent to participate}

All protocols for working with MA-INTACT mice were approved by UGA's Institutional Animal Care and Use Committee (IACUC \#A2014-07-023-Y2-A1) and follow the United States Government's Policy on Humane Care and Use of Animals, which regulates the use of vertebrate animals for research.

\section{Author details}

'Department of Genetics, University of Georgia, Athens, GA, USA

2Department of Foods and Nutrition, University of Georgia, Athens, GA, USA.

${ }^{3}$ Department of Animal and Dairy Science, University of Georgia, Athens, GA, USA.

Received: 18 December 2015 Accepted: 16 June 2016

\section{Published online: 19 July 2016}

\section{References}

1. Adamczak M, Wiecek $A$. The adipose tissue as an endocrine organ. Semin Nephrol. 2013;33(1):2-13

2. Coelho M, Oliveira T, Fernandes R. Biochemistry of adipose tissue: an endocrine organ. Arch Med Sci. 2013;9(2):191-200.

3. McGown C, Birerdinc A, Younossi ZM. Adipose tissue as an endocrine organ. Clin Liver Dis. 2014;18(1):41-58.

4. Goyal A, Nimmakayala KR, Zonszein J. Is there a paradox in obesity? Cardiol Rev. 2014;22(4):163-70

5. Gil A, Olza J, Gil-Campos M, Gomez-Llorente C, Aguilera CM. Is adipose tissue metabolically different at different sites? Int J Pediatr Obes. 2011;6 Suppl 1:13-20

6. Chau YY, Bandiera R, Serrels A, Martinez-Estrada OM, Qing W, Lee M, Slight J, Thornburn A, Berry R, McHaffie S, et al. Visceral and subcutaneous fat have different origins and evidence supports a mesothelial source. Nat Cell Biol. 2014;16(4):367-75.

7. Macotela Y, Emanuelli B, Mori MA, Gesta S, Schulz TJ, Tseng YH, Kahn CR Intrinsic differences in adipocyte precursor cells from different white fat depots. Diabetes. 2012;61(7):1691-9.

8. Baglioni S, Cantini G, Poli G, Francalanci M, Squecco R, Di Franco A, Borgogni E, Frontera S, Nesi G, Liotta F, et al. Functional differences in visceral and subcutaneous fat pads originate from differences in the adipose stem cell. PLoS One. 2012;7(5):e36569.

9. Gesta S, Bluher M, Yamamoto Y, Norris AW, Berndt J, Kralisch S, Boucher J, Lewis C, Kahn CR. Evidence for a role of developmental genes in the origin of obesity and body fat distribution. Proc Natl Acad Sci U S A. 2006;103(17):6676-81.

10. Gerhard GS, Styer AM, Strodel WE, Roesch SL, Yavorek A, Carey DJ, Wood GC Petrick AT, Gabrielsen J, Ibele A, et al. Gene expression profiling in subcutaneous, visceral and epigastric adipose tissues of patients with extreme obesity. Int J Obes (Lond). 2014;38(3):371-8.

11. Balistreri CR, Caruso C, Candore G. The role of adipose tissue and adipokines in obesity-related inflammatory diseases. Mediators Inflamm. 2010;2010:802078.

12. Khan M, Joseph F. Adipose tissue and adipokines: the association with and application of adipokines in obesity. Scientifica. 2014;2014:328592.

13. Northcott JM, Yeganeh A, Taylor CG, Zahradka P, Wigle JT. Adipokines and the cardiovascular system: mechanisms mediating health and disease. Can J Physiol Pharmacol. 2012;90(8):1029-59.

14. Ahima RS. Adipose Tissue as an Endocrine Organ. Obesity. 2012;14:242S-9.

15. Sethi JK, Vidal-Puig A. Visfatin: the missing link between intra-abdominal obesity and diabetes? Trends Mol Med. 2005;11(8):344-7.

16. Boydens C, Maenhaut N, Pauwels B, Decaluwe K, Van de Voorde J. Adipose tissue as regulator of vascular tone. Curr Hypertens Rep. 2012;14(3):270-8.

17. Matsuda M, Shimomura I. Roles of adiponectin and oxidative stress in obesity-associated metabolic and cardiovascular diseases. Rev Endocr Metab Disord. 2014;15(1):1-10.

18. Van de Voorde J, Pauwels B, Boydens C, Decaluwe K. Adipocytokines in relation to cardiovascular disease. Metabolism. 2013;62(11):1513-21.

19. Fietta P, Delsante G. Focus on adipokines. Theor Biol Forum. 2013;106(1-2):103-29.

20. Ma X, Lee P, Chisholm DJ, James DE. Control of adipocyte differentiation in different fat depots; implications for pathophysiology or therapy. Front Endocrinol (Lausanne). 2015:6:1.

21. Cohen P, Levy JD, Zhang Y, Frontini A, Kolodin DP, Svensson KJ, Lo JC, Zeng X, Ye L, Khandekar MJ, et al. Ablation of PRDM16 and beige adipose causes metabolic dysfunction and a subcutaneous to visceral fat switch. Cell. 2014;156(1-2):304-16.

22. Zafrir B. Brown Adipose Tissue: Research Milestones of a Potential Player in Human Energy Balance and Obesity. Horm Metab Res. 2013.

23. Greenberg AS, Obin MS. Obesity and the role of adipose tissue in inflammation and metabolism. Am J Clin Nutr. 2006;83(2):461S-5.

24. Grant RW, Dixit VD. Adipose tissue as an immunological organ. Obesity (Silver Spring). 2015;23(3):512-8.

25. De Pergola G, Silvestris F. Obesity as a major risk factor for cancer. J Obes. 2013;2013:291546

26. Haig D. The (dual) origin of epigenetics. Cold Spring Harb Symp Quant Biol. 2004;69:67-70

27. Southall TD, Gold KS, Egger B, Davidson CM, Caygill EE, Marshall OJ, Brand $\mathrm{AH}$. Cell-type-specific profiling of gene expression and chromatin binding without cell isolation: assaying RNA Pol II occupancy in neural stem cells. Dev Cell. 2013;26(1):101-12.

28. Deal RB, Henikoff S. A Simple Method for Gene Expression and Chromatin Profiling of Individual Cell Types within a Tissue. Dev Cell. 2010;18(6):1030-40

29. Dammer EB, Duong DM, Diner I, Gearing M, Feng Y, Lah JJ, Levey Al, Seyfried NT. Neuron enriched nuclear proteome isolated from human brain. J Proteome Res. 2013;12(7):3193-206.

30. Yu P, McKinney EC, Kandasamy MM, Albert AL, Meagher RB. Characterization of brain cell nuclei with decondensed chromatin. Dev Neurobiol. 2015;75(7):738-56.

31. Merbs SL, Khan MA, Hackler Jr L, Oliver VF, Wan J, Qian J, Zack DJ. Cell-specific DNA methylation patterns of retina-specific genes. PLoS One. 2012;7(3), e32602

32. Reinius LE, Acevedo N, Joerink M, Pershagen G, Dahlen SE, Greco D, Soderhall C, Scheynius A, Kere J. Differential DNA methylation in purified human blood cells: implications for cell lineage and studies on disease susceptibility. PLoS One. 2012;7(7), e41361.

33. Jeffries MA, Dozmorov M, Tang Y, Merrill JT, Wren JD, Sawalha AH. Genomewide DNA methylation patterns in CD4+ T cells from patients with systemic lupus erythematosus. Epigenetics. 2011;6(5):593-601.

34. Altorok N, Coit P, Hughes T, Koelsch KA, Stone DU, Rasmussen A, Radfar L, Scofield RH, Sivils KL, Farris AD, et al. Genome-wide DNA methylation patterns in naive CD4+ T cells from patients with primary Sjogren's syndrome. Arthritis \& rheumatology. 2014:66(3):731-9.

35. Javierre BM, Fernandez AF, Richter J, Al-Shahrour F, Martin-Subero الJ, Rodriguez-Ubreva J, Berdasco M, Fraga MF, O'Hanlon TP, Rider LG, et al. Changes in the pattern of DNA methylation associate with twin discordance in systemic lupus erythematosus. Genome Res. 2010:20(2):170-9. 
36. Zha L, Li F, Wu R, Artinian L, Rehder V, Yu L, Liang H, Xue B, Shi $H$. The Histone Demethylase UTX Promotes Brown Adipocyte Thermogenic Program Via Coordinated Regulation of H3K27 Demethylation and Acetylation. J Biol Chem. 2015;290(41):25151-63.

37. Arner P, Sinha I, Thorell A, Ryden M, Dahlman-Wright K, Dahlman I. The epigenetic signature of subcutaneous fat cells is linked to altered expression of genes implicated in lipid metabolism in obese women. Clin Epigenetics. 2015;7(1):93.

38. Katz LS, Geras-Raaka E, Gershengorn MC. Heritability of fat accumulation in white adipocytes. Am J Physiol Endocrinol Metab. 2014;307(3):E335-44.

39. Pinnick KE, Karpe F. DNA methylation of genes in adipose tissue. Proc Nutr Soc. 2011;70(1):57-63.

40. Slyvka Y, Zhang Y, Nowak FV. Epigenetic effects of paternal diet on offspring: emphasis on obesity. Endocrine. 2015;48(1):36-46.

41. Nicoletti CF, Nonino CB, de Oliveira BA, Pinhel MA, Mansego ML, Milagro FI, et al. DNA Methylation and Hydroxymethylation Levels in Relation to Two Weight Loss Strategies: Energy-Restricted Diet or Bariatric Surgery. Obes Surg. 2015.

42. Cordero P, Li J, Oben JA. Epigenetics of obesity: beyond the genome sequence. Curr Opin Clin Nutr Metab Care. 2015;18(4):361-6.

43. Horvath S, Erhart W, Brosch M, Ammerpohl O, von Schonfels W, Ahrens M Heits N, Bell JT, Tsai PC, Spector TD, et al. Obesity accelerates epigenetic aging of human liver. Proc Natl Acad Sci U S A. 2014;111(43):15538-43.

44. Inzaugarat ME, Billordo LA, Vodanovich F, Cervini GM, Casavalle PL, Vedire C, Chernavsky AC. Alterations in innate and adaptive immune leukocytes are involved in paediatric obesity. Pediatric obesity. 2013.

45. Lumeng CN, Liu J, Geletka L, Delaney C, Delproposto J, Desai A, et al. Aging Is Associated with an Increase in T Cells and Inflammatory Macrophages in Visceral Adipose Tissue. J Immunol. 2011.

46. Anderson EK, Gutierrez DA, Hasty AH. Adipose tissue recruitment of leukocytes. Curr Opin Lipidol. 2010;21(3):172-7.

47. McCusker RH, Campion DR, Cartwright AL. Effect of growth hormonesecreting tumors on adipose tissue cellularity in young and mature rats. Growth. 1986;50(1):128-37.

48. Liu W, Shan T, Yang X, Liang S, Zhang P, Liu Y, Liu X, Kuang S. A heterogeneous lineage origin underlies the phenotypic and molecular differences of white and beige adipocytes. J Cell Sci. 2013;126(Pt 16):3527-32

49. Kajita K, Mori I, Kitada Y, Taguchi K, Kajita T, Hanamoto T, Ikeda T, Fujioka K, Yamauchi M, Okada $\mathrm{H}$, et al. Small proliferative adipocytes: identification of proliferative cells expressing adipocyte markers [Review]. Endocr J. 2013;60(8):931-9.

50. Wei S, Zan L, Hausman GJ, Rasmussen TP, Bergen WG, Dodson MV. Dedifferentiated adipocyte-derived progeny cells (DFAT cells): Potential stem cells of adipose tissue. Adipocyte. 2013;2(3):122-7.

51. Wei S, Du M, Jiang Z, Duarte MS, Fernyhough-Culver M, Albrecht E, Will K, Zan L, Hausman GJ, Elabd EM, et al. Bovine dedifferentiated adipose tissue (DFAT) cells: DFAT cell isolation. Adipocyte. 2013;2(3):148-59.

52. Deal RB, Henikoff S. The INTACT method for cell type-specific gene expression and chromatin profiling in Arabidopsis thaliana. Nat Protoc. 2011;6(1):56-68

53. Henry GL, Davis FP, Picard S, Eddy SR. Cell type-specific genomics of Drosophila neurons. Nucleic Acids Res. 2012;40(19):9691-704.

54. Steiner FA, Henikoff S. Cell type-specific affinity purification of nuclei for chromatin profiling in whole animals. Methods Mol Biol. 2015;1228:3-14.

55. Harlow E, Lane D. Antibodies : a laboratory manual. Cold Spring Harbor: Cold Spring Harbor Laboratory; 1988.

56. Yu P, Ji L, Lee KJ, Yu M, He C, Ambati S, McKinney EC, Jackson C, Baile CA, Schmitz RJ et al: Subsets of Visceral Adipose Tissue Nuclei with Distinct Levels of 5-Hydroxymethylcytosine. PLoS One. 2016;11(5):e0154949.

57. Vandesompele J, De Preter K, Pattyn F, Poppe B, Van Roy N, De Paepe A, Speleman F: Accurate normalization of real-time quantitative RT-PCR data by geometric averaging of multiple internal control genes. Genome Biol. 2002;3(7):RESEARCH0034.

58. Nagaraju GP, Aliya S, Alese OB. Role of adiponectin in obesity related gastrointestinal carcinogenesis. Cytokine Growth Factor Rev. 2015;26(1):83-93.

59. Fasshauer M, Klein J, Neumann S, Eszlinger M, Paschke R. Adiponectin gene expression is inhibited by beta-adrenergic stimulation via protein kinase $\mathrm{A}$ in 3 T3-L1 adipocytes. FEBS Lett. 2001;507(2):142-6.

60. Koshiishi C, Park HM, Uchiyama H, Tanaka Y. Regulation of expression of the mouse adiponectin gene by the C/EBP family via a novel enhancer region. Gene. 2008;424(1-2):141-6.
61. Qiao L, Yoo H, Bosco C, Lee B, Feng GS, Schaack J, Chi NW, Shao J. Adiponectin reduces thermogenesis by inhibiting brown adipose tissue activation in mice. Diabetologia. 2014;57(5):1027-36.

62. Paschke L, Zemleduch T, Rucinski M, Ziolkowska A, Szyszka M, Malendowicz LK. Adiponectin and adiponectin receptor system in the rat adrenal gland: ontogenetic and physiologic regulation, and its involvement in regulating adrenocortical growth and steroidogenesis. Peptides. 2010;31(9):1715-24.

63. Wang ZV, Deng Y, Wang QA, Sun K, Scherer PE. Identification and characterization of a promoter cassette conferring adipocyte-specific gene expression. Endocrinology. 2010;151(6):2933-9.

64. Campbell RE, Tour O, Palmer AE, Steinbach PA, Baird GS, Zacharias DA, Tsien RY. A monomeric red fluorescent protein. Proc Natl Acad Sci U S A. 2002;99(12):7877-82

65. Agardh HE, Gertow K, Salvado DM, Hermansson A, van Puijvelde GH, Hansson GK, Berne GP, Gabrielsen A. Fatty acid binding protein 4 in circulating leucocytes reflects atherosclerotic lesion progression in Apoe(-/-) mice. J Cell Mol Med. 2013;17(2):303-10.

66. Vohl MC, Sladek R, Robitaille J, Gurd S, Marceau P, Richard D, Hudson TJ, Tchernof A. A survey of genes differentially expressed in subcutaneous and visceral adipose tissue in men. Obes Res. 2004;12(8):1217-22.

67. Atzmon G, Yang XM, Muzumdar R, Ma XH, Gabriely I, Barzilai N. Differential gene expression between visceral and subcutaneous fat depots. Horm Metab Res. 2002;34(11-12):622-8.

68. Ahfeldt T, Schinzel RT, Lee YK, Hendrickson D, Kaplan A, Lum DH, Camahort R, Xia F, Shay J, Rhee EP, et al. Programming human pluripotent stem cells into white and brown adipocytes. Nat Cell Biol. 2012;14(2):209-19.

69. Wu J, Srinivasan SV, Neumann JC, Lingrel JB. The KLF2 transcription factor does not affect the formation of preadipocytes but inhibits their differentiation into adipocytes. Biochemistry. 2005:44(33):11098-105.

70. Kurebayashi S, Sumitani S, Kasayama S, Jetten AM, Hirose T. TNF-alpha inhibits 3 T3-L1 adipocyte differentiation without downregulating the expression of C/EBPbeta and delta. Endocr J. 2001:48(2):249-53.

71. Ruan H, Hacohen N, Golub TR, Van Parijs L, Lodish HF. Tumor necrosis factor-alpha suppresses adipocyte-specific genes and activates expression of preadipocyte genes in 3 T3-L1 adipocytes: nuclear factor-kappaB activation by TNF-alpha is obligatory. Diabetes. 2002;51(5):1319-36.

72. Menzaghi C, Bacci S, Salvemini L, Mendonca C, Palladino G, Fontana A, De Bonis C, Marucci A, Goheen E, Prudente S, et al. Serum resistin, cardiovascular disease and all-cause mortality in patients with type 2 diabetes. PLoS One. 2014;8(6), e64729.

73. Fontana A, Spadaro S, Copetti M, Spoto B, Salvemini L, Pizzini P, Frittitta L, Mallamaci $F$, Pellegrini $F$, Trischitta $V$, et al. Association between resistin levels and all-cause and cardiovascular mortality: a new study and a systematic review and meta-analysis. PLoS One. 2015;10(3), e0120419.

74. Kaur P, Reis MD, Couchman GR, Forjuoh SN, Greene JF, Asea A. SERPINE 1 Links Obesity and Diabetes: A Pilot Study. J Proteomics Bioinform. 2010;3(6):191-9.

75. Than A, He HL, Chua SH, Xu D, Sun L, Leow MK, Chen P. Apelin Enhances Brown Adipogenesis and Browning of White Adipocytes. J Biol Chem. 2015; 290(23):14679-91.

76. Cancello R, Zingaretti MC, Sarzani R, Ricquier D, Cinti S. Leptin and UCP1 genes are reciprocally regulated in brown adipose tissue. Endocrinology. 1998;139(11):4747-50.

77. Mohsen-Kanson T, Hafner AL, Wdziekonski B, Takashima Y, Villageois P, Carriere A, et al. Differentiation of human induced pluripotent stem cells into brown and white adipocytes: Role of Pax3. Stem Cells. 2013.

78. Basse AL, Dixen K, Yadav R, Tygesen MP, Qvortrup K, Kristiansen K, Quistorff B, Gupta R, Wang J, Hansen JB. Global gene expression profiling of brown to white adipose tissue transformation in sheep reveals novel transcriptional components linked to adipose remodeling. BMC Genomics. 2015;16:215.

79. Guo W, Zhang KM, Tu K, Li YX, Zhu L, Xiao HS, Yang Y, Wu JR. Adipogenesis licensing and execution are disparately linked to cell proliferation. Cell Res. 2009:19(2):216-23.

80. Fujiki K, Kano F, Shiota K, Murata M. Expression of the peroxisome proliferator activated receptor gamma gene is repressed by DNA methylation in visceral adipose tissue of mouse models of diabetes. BMC Biol. 2009:7:38.

81. Sun $R$, Wu Y, Wang Y, Zang K, Wei H, Wang F, Yu M. DNA methylation regulates bromodomain-containing protein 2 expression during adipocyte differentiation. Mol Cell Biochem. 2015;402(1-2):23-31. 
82. Hildrestrand GA, Duggal S, Bjoras M, Luna L, Brinchmann JE. Modulation of DNA glycosylase activities in mesenchymal stem cells. Exp Cell Res. 2009;315(15):2558-67.

83. Okamura $M$, Inagaki T, Tanaka T, Sakai J. Role of histone methylation and demethylation in adipogenesis and obesity. Organogenesis. 2010; 6(1):24-32.

84. Zhang Q, Ramlee MK, Brunmeir R, Villanueva CJ, Halperin D, Xu F. Dynamic and distinct histone modifications modulate the expression of key adipogenesis regulatory genes. Cell Cycle. 2012;11(23):4310-22.

85. LeBlanc SE, Konda S, Wu Q, Hu YJ, Oslowski CM, Sif S, Imbalzano AN. Protein arginine methyltransferase 5 (Prmt5) promotes gene expression of peroxisome proliferator-activated receptor gamma2 (PPARgamma2) and its target genes during adipogenesis. Mol Endocrinol. 2012;26(4):583-97.

86. Ibrahim MM. Subcutaneous and visceral adipose tissue: structural and functional differences. Obes Rev. 2010;11(1):11-8.

87. Rockstroh D, Landgraf K, Wagner IV, Gesing J, Tauscher R, Lakowa N, Kiess W, Buhligen $U$, Wojan M, Till H, et al. Direct evidence of brown adipocytes in different fat depots in children. PLoS One. 2015;10(2), e0117841.

88. Sharp LZ, Shinoda K, Ohno H, Scheel DW, Tomoda E, Ruiz L, Hu H, Wang L, Pavlova Z, Gilsanz V, et al. Human BAT Possesses Molecular Signatures That Resemble Beige/Brite Cells. PLoS One. 2012;7(11), e49452.

89. Wang QA, Tao C, Gupta RK, Scherer PE. Tracking adipogenesis during white adipose tissue development, expansion and regeneration. Nat Med. 2013; 19(10):1338-44.

90. Ye L, Wu J, Cohen P, Kazak L, Khandekar MJ, Jedrychowski MP, Zeng X, Gygi SP, Spiegelman BM. Fat cells directly sense temperature to activate thermogenesis. Proc Natl Acad Sci U S A. 2013;110(30):12480-5.

91. Londono Gentile T, Lu C, Lodato PM, Tse S, Olejniczak SH, Witze ES, Thompson CB, Wellen KE. DNMT1 is regulated by ATP-citrate lyase and maintains methylation patterns during adipocyte differentiation. Mol Cell Biol. 2013;33(19):3864-78.

92. Zych J, Stimamiglio MA, Senegaglia AC, Brofman PR, Dallagiovanna B, Goldenberg S, Correa A. The epigenetic modifiers 5-aza-2'-deoxycytidine and trichostatin $\mathrm{A}$ influence adipocyte differentiation in human mesenchymal stem cells. Braz J Med Biol Res. 2013:46(5):405-16.

93. Kaur K, Yang J, Eisenberg CA, Eisenberg LM. 5-azacytidine promotes the transdifferentiation of cardiac cells to skeletal myocytes. Cell Reprogram. 2014;16(5):324-30.

94. Meagher RB. 'Memory and molecular turnover', 30 years after inception. Epigenetics Chromatin. 2014;7(1):37-45.

95. Takada I, Kouzmenko AP, Kato S. Molecular switching of osteoblastogenesis versus adipogenesis: implications for targeted therapies. Expert Opin Ther Targets. 2009;13(5):593-603.

96. Tan MK, Lim HJ, Harper JW. SCF(FBXO22) regulates histone H3 lysine 9 and 36 methylation levels by targeting histone demethylase KDM4A for ubiquitin-mediated proteasomal degradation. Mol Cell Biol. 2011; 31(18):3687-99.

97. Zhang ZC, Liu Y, Li SF, Guo L, Zhao Y, Qian SW, Wen B, Tang QQ, Li X Suv39h1 mediates AP-2alpha-dependent inhibition of C/EBPalpha expression during adipogenesis. Mol Cell Biol. 2014;34(12):2330-8.

98. Cardamone MD, Tanasa B, Chan M, Cederquist CT, Andricovich J, Rosenfeld MG Perissi V. GPS2/KDM4A pioneering activity regulates promoter-specific recruitment of PPARgamma. Cell Rep. 2014;8(1):163-76.

99. Kim D, Lee J, Cheng D, Li J, Carter C, Richie E, Bedford MT. Enzymatic activity is required for the in vivo functions of CARM1. J Biol Chem. 2010;285(2):1147-52

100. Kang I, Okla M, Chung S. Ellagic acid inhibits adipocyte differentiation through coactivator-associated arginine methyltransferase 1-mediated chromatin modification. J Nutr Biochem. 2014;25(9):946-53.

101. Hu YJ, Sif S, Imbalzano AN. Prmt7 is dispensable in tissue culture models for adipogenic differentiation. F1000Research. 2013;2:279.

102. Yu Z, Chen T, Hebert J, Li E, Richard S. A mouse PRMT1 null allele defines an essential role for arginine methylation in genome maintenance and cell proliferation. Mol Cell Biol. 2009;29(11):2982-96.

103. Avasarala S, Van Scoyk M, Karuppusamy Rathinam MK, Zerayesus S, Zhao X, Zhang W, Pergande MR, Borgia JA, DeGregori J, Port JD, et al. PRMT1 Is a Novel Regulator of Epithelial-Mesenchymal-Transition in Non-small Cell Lung Cancer. J Biol Chem. 2015;290(21):13479-89.
104. Sun Q, Liu L, Roth M, Tian J, He Q, Zhong B, Bao R, Lan X, Jiang C, Sun J, et al. PRMT1 Upregulated by Epithelial Proinflammatory Cytokines Participates in COX2 Expression in Fibroblasts and Chronic Antigen-Induced Pulmonary Inflammation. J Immunol. 2015;195(1):298-306.

105. Livak KJ, Schmittgen TD. Analysis of relative gene expression data using real-time quantitative PCR and the 2(-Delta Delta C(T)) Method. Methods. 2001;25(4):402-8.

\section{Submit your next manuscript to BioMed Central and we will help you at every step:}

- We accept pre-submission inquiries

- Our selector tool helps you to find the most relevant journal

- We provide round the clock customer support

- Convenient online submission

- Thorough peer review

- Inclusion in PubMed and all major indexing services

- Maximum visibility for your research

Submit your manuscript at www.biomedcentral.com/submit
Biomed Central 